\title{
A multifactorial analysis of differential agent marking in Herodotus
}

\author{
David Goldstein | ORCID: 0000-0003-1276-7623 \\ University of California, Los Angeles, CA, USA \\ dgoldstein@humnet.ucla.edu
}

\begin{abstract}
Passive agents in ancient Greek exhibit a well-known alternation between dative case and prepositional phrase. It has long been recognized that grammatical aspect plays a crucial role in this alternation: dative agents preponderate among aspectually perfect predicates, prepositional phrase agents elsewhere. Although the importance of grammatical aspect is undeniable, it is not the only factor that determines the realization of passive agents. The identification of other factors has proven challenging, however, not least because previous researchers have lacked methods for assessing the relative importance of the determinants that influence the realization of agent phrases. In this paper, I use Bayesian mixed-effects logistic regression to provide a multifactorial account of differential agent marking in Herodotus, according to which the realization of passive agent phrases is conditioned by the relationship between semantic role and referential prominence (Haspelmath 2021). Dative agents are favored in clauses where semantic role and referential prominence are aligned (i.e., the agent is referentially prominent or the patient is referentially non-prominent). By contrast, prepositional phrase agents are more likely when semantic role and referential prominence are at odds (i.e., the patient is referentially prominent or the agent is referentially non-prominent).
\end{abstract}

\section{Keywords}

Herodotus - linguistic variation - differential agent marking - passive - mixed-effects logistic regression 


\section{Introduction}

Agents of passive verbs in ancient Greek can be realized in one of two ways, with the dative case or with a prepositional phrase, as illustrated by the following pair of examples from Herodotus: ${ }^{1}$

(1) Differential agent marking

a. Dative agent

$\dot{\eta} \delta \dot{\varepsilon} \quad \delta \delta \dot{s} s \quad \dot{\eta}$

DEF.ART.NOM.SG PTCL journey.NOM.SG DEF.ART.NOM.SG

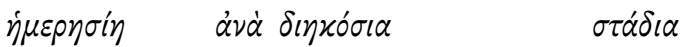

daily.NOM.SG at two.hundred.ACC.PL stade.ACC.PL

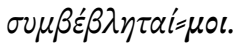

calculate.3SG.PRF.MED.IN D=1SG.DAT

'The day's journey has been calculated by me at 200 stades.' (Hdt. 4.101.3)

b. Prepositional phrase agent

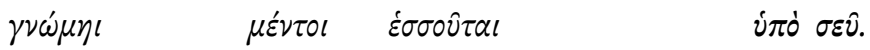

counsel.DAT.SG however best.3SG.PRES.MED.IND by 2SG.GEN

'In counsel, however, he is bested by you.' (Hdt. 7.237.1)

In example (1a), the passive agent is realized by the dative pronoun = $\mu$ ol 'by me'. In example ( $(\mathrm{b})$, the passive agent is realized by the prepositional phrase $i \pi \dot{0}$ $\sigma \varepsilon \hat{v}$ 'by you'. The goal of this paper is to identify and motivate the factors that condition the realization of passive agent phrases in Herodotus.

Before introducing the previous research on differential agent marking in Greek, it is worth laying out a few basic properties of the alternation. First, prepositional phrase agents are more than twice as frequent as dative agents in Herodotus, as shown by Figure 1. Second, the distribution of prepositions among prepositional phrase agents is highly skewed. The vast majority are headed by i $\pi$ ó, as Figure 2 reveals. (Prepositions were only counted once for

1 The following abbreviations are used in the glosses: 1: first person, 2: second person, 3: third person, AD: adelative, ADD: additive, ABL: ablative, ABS: absolutive, ACC: accusative, ACT: active, ADV: adverb, AOR: aorist, ART: article, COMP: complementizer, CONJ: conjunction, DAT: dative, DEF: definite article, DEM: demonstrative, ELAT: elative, ERG: ergative, GEN: genitive, GNDV: gerundive, IM PF: imperfect, IMPV: imperative, INDF: indefinite, MASC: masculine, MED: mediopassive, NEG: negation, NOM: nominative, PASS: passive, PLPF: pluperfect, POss: possessive, PRF: perfect, PRES: present, PST: past, PTCL: particle, PTCP: participle, REL: relative pronoun, SG: singular, SBJV: subjunctive, voc: vocative. I would like to thank Denys CennetPlanchard for his assistance with the glosses. 


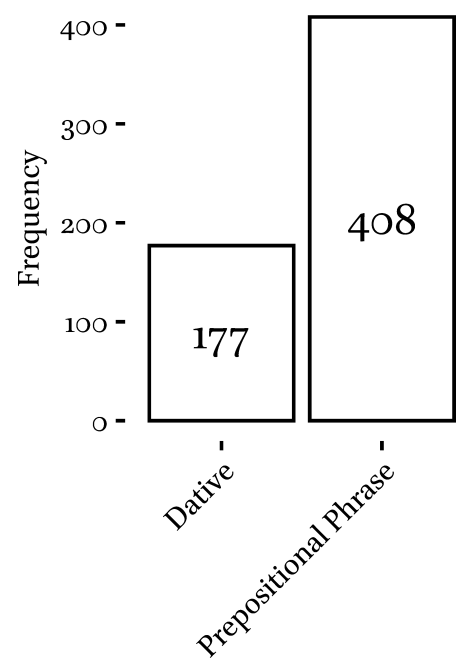

FIGURE 1 Passive agent expression in Herodotus

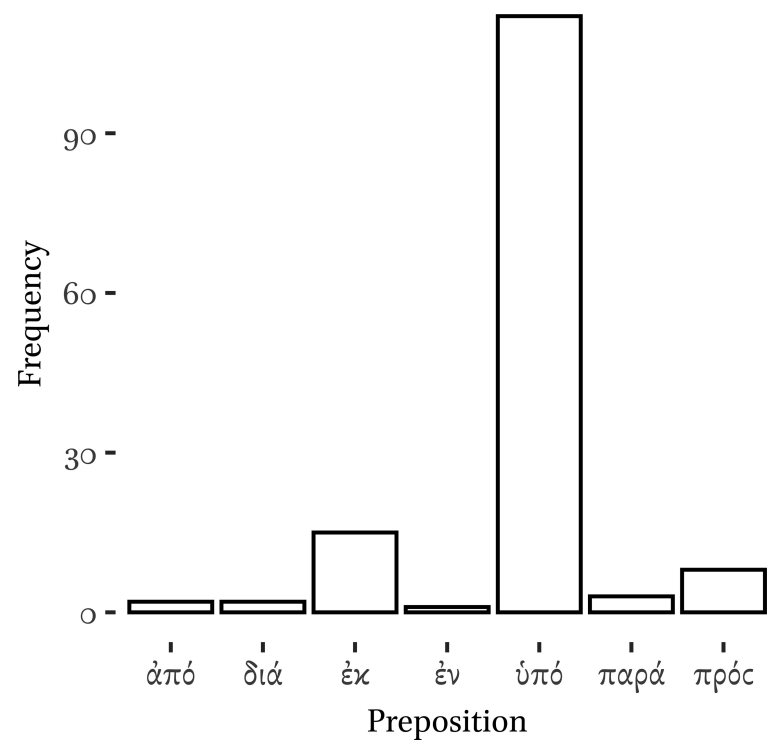

FIGURE 2 The frequency distribution of prepositions among prepositional phrase agents in Herodotus

each verb with which they co-occurred.) The predominance of i $\pi$ ó in classical Greek distinguishes this stage of the language from Homeric Greek, where

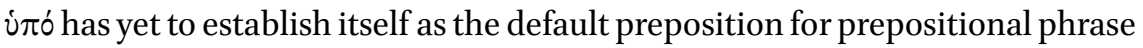
agents, and modern Greek, where prepositional phrase agents are now headed by $\alpha \pi$ ó. 
Finally, the same predicate can co-occur with both a dative and a prepositional phrase agent:

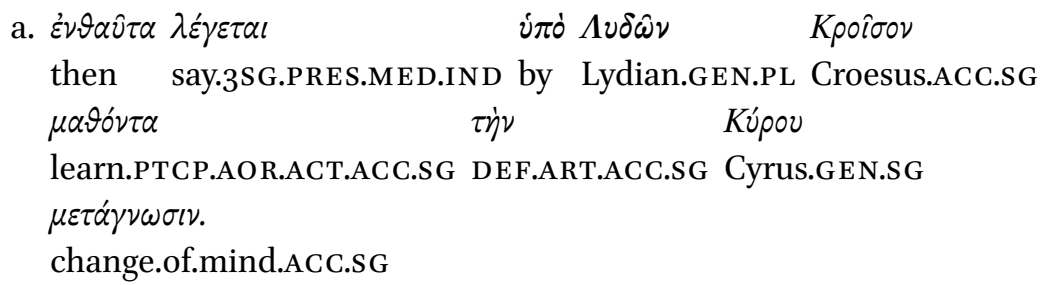

'It is said by Lydians that Croesus then understood Cyrus' reversal.' (Hdt. 1.87.1)

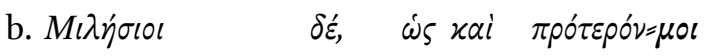

Milesian.NOM.PL PTCL as ADD before.ACC.SG=1SG.DAT

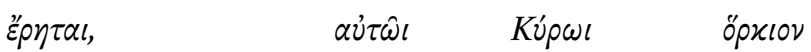

say.3SG.PRF.MED.IND self.DAT.sG Cyrus.DAT.SG oath.ACC.SG

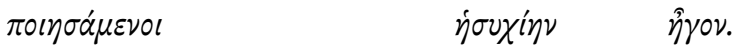

make.PTCP.AOR.MED.NOM.PL peace.ACC.SG do.3PL.IMPF.IND.ACT

'The Milesians, having pledged an oath to Cyrus himself, were at peace, as has also been said by me before.' (Hdt. 1.169.2)

The predicate $\lambda \dot{\varepsilon} \gamma \omega$ 'say' co-occurs with a prepositional phrase agent in example (2a) and a dative agent in example ( $2 \mathrm{~b}$ ). Figure 3 presents the distribution of dative and prepositional phrase agents in Herodotus for predicates that are attested at least four times with an overt passive agent.

It has long been held that the central determinant of passive agent phrases is grammatical aspect: dative agents occur in the presence of a perfect predicate and prepositional phrase agents elsewhere (e.g., Kühner \& Gerth 1898: 422; Schwyzer 1988: 149-150; Smyth 1956: §§1488, 149o; George 2005: 1, 78). So in

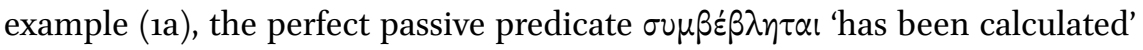
co-occurs with the dative agent $\mu$ or 'by me'. In ( $1 \mathrm{~b})$, the prepositional phrase agent $\dot{\pi}$ ò $\sigma \varepsilon \hat{\vartheta}$ 'by you' is conditioned by the present imperfective $\dot{\varepsilon} \sigma \sigma \circ \hat{\tau} \tau \mathrm{ll}$ 'is bested. ${ }^{2}$

2 The correlation between dative agents and perfect aspect suggests prima facie that classical Greek may not be a strict accusative-alignment language. Malchukov \& Hoop (2011: 41) mention a few languages in which non-accusative patterns are found in the perfect. However, there is no evidence in Greek (e.g., on the basis of control or agreement) to suggest that dative agents (or prepositional phrase agents, for that matter) are syntactic subjects. There is therefore no reason to doubt that Greek is a nominative-accusative language. Farther afield, attempts to reconstruct ergative alignment to Proto-Indo-European or Pre-Proto-IndoEuropean have failed (pace, e.g., Bavant 2008; Willi 2018). 


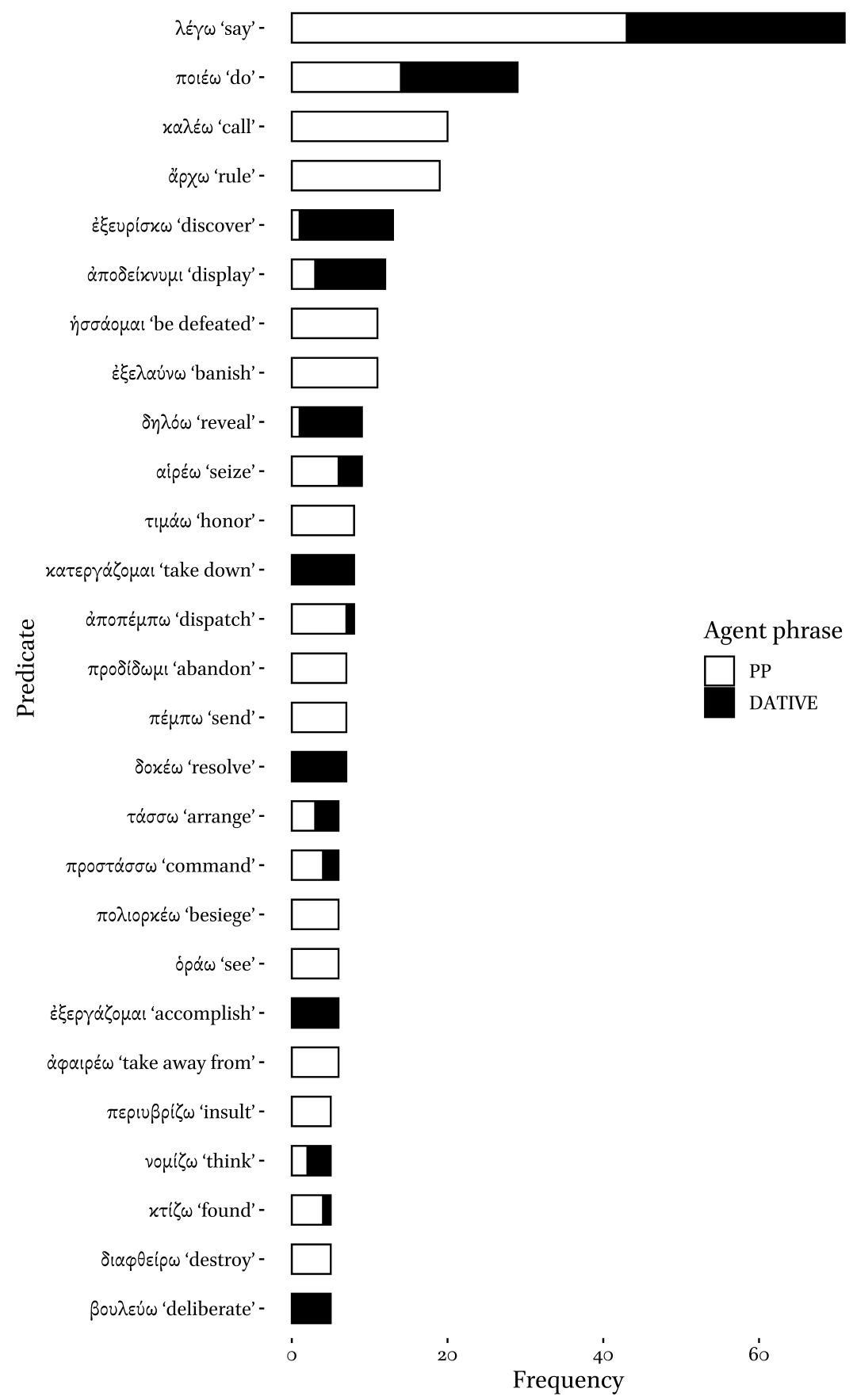

FIGURE 3 The frequency distribution of passive agent marking according to predicate in Herodotus 
Although grammatical aspect plays an important role in the realization of the passive agents, it is not the whole story, since counterexamples occur in both directions:

(3) Counterexamples

a. PP-agent with perfect

$\dot{\varepsilon} \xi \varepsilon \lambda \eta \lambda \alpha \mu \dot{\varepsilon} v \circ \varsigma \quad \tau \varepsilon \quad$ í $\pi \dot{o} \tau 0 \hat{v}$

banish.PTCP.PRF.MED.NOM.SG CONJ by DEF.ART.GEN.SG

$\pi \alpha \tau \rho \dot{\rho} s$

father.GEN.SG

'And having been banished by my father, I ...' (Hdt. 1.35.3)

b. Dative agent with non-perfect (perfective)

$i \delta \rho v \vartheta \varepsilon v \tau \tau \nu \nu \quad \delta \dot{\varepsilon}=\sigma \varphi l \quad i \rho \omega \nu$

establish.PTCP.AOR.PASS.GEN.PL PTCL=3PL.DAT temple.GEN.PL

$\xi \varepsilon v(x \omega \hat{\omega} \nu$

foreign.GEN.PL

'After foreign temples had been established by them ...' (Hdt. 1.172.2)

The traditional account predicts a dative agent in example (3a) on account of

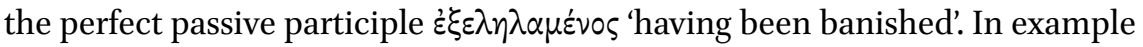
$(3 \mathrm{~b})$, a prepositional phrase agent is predicted with the aorist passive participle

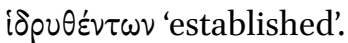

To improve empirical coverage, subsequent research has attempted to identify the factors beyond aspect that influence the realization of the agent phrase. George (2005), for instance, argues that in addition to aspect, the pronominality of the agent phrase, the animacy of the patient, and the finiteness of the passive predicate all play a role in the selection of passive agents. In addition, George attempts to motivate differential agent marking in classical Greek by arguing that prepositional phrase agents are used when the dative case alone is insufficient to discriminate between the agent and the patient. This happens in particular when the agent and the patient are animate, since both participants are plausible candidates for the agent. In such a context, a prepositional phrase is therefore used as an unequivocal signal of agency.

George's model is a decided improvement on the traditional account, but is not without its own problems. For one, his account predicts an association between dative agents and participial predicates, but examination of a wider swath of data reveals that such an association is at best questionable. Another issue is that the determinants of passive agent realization identified by George (2005) are not all of equal importance: some have a greater association with a 
particular form of passive agent than others. George, however, lacks a method for assessing the relative importance of the factors that contribute to the realization of passive agents.

\subsection{A new approach}

Building on insights from differential marking in the typological and theoretical literature (e.g., Bossong 1985; Bossong 1991; Aissen 2003), I pursue a novel analysis at the heart of which is the relationship between semantic role and referential prominence (Haspelmath 2021). Arguments with a highly ranked semantic role (such as an agent) usually exhibit more referential prominence (e.g., they are definite). Lower-ranked arguments (such as patients) tend in turn to be less referentially prominent (e.g., they are indefinite). When these rolereference associations obtain, the passive agent in Herodotus is more likely to be realized with a case marker (i.e., as a dative agent). When they do not obtain, the passive agent is more likely to be realized with both a case marker and a prepositional phrase (i.e., as a prepositional phrase agent). In other words, the shorter coding of passive agents predominates among clauses exhibiting typical role-reference associations and the longer coding in clauses that deviate from these associations.

The crucial question for my approach is what constitutes referential prominence and I argue for the importance of the following four factors: grammatical aspect, patient animacy, agent nominality, and the prosodic realization of the agent. The first three factors are adopted from the traditional account and the work of George (2005). The final factor is not only new, but also turns out to be the most important predictor of passive agent realization. The association between enclitic pronouns and dative agents is stronger than any other factor-including that of perfect aspect.

As mentioned in the previous section, assessing the strength of predictor variables is difficult without quantitative data (Gries 2003: 46), which has only played a minor role in previous studies of differential agent marking in Greek. In my analysis, quantitative data plays a central role. I offer the first multifactorial account of passive agent realization in Herodotus using Bayesian mixedeffects logistic regression (for a similar approach to linguistic variation, see, e.g., Bresnan et al. 2007; Wolk et al. 2013; Brookes 2014). ${ }^{3}$ Regression modeling casts the alternation between dative and prepositional phrase agents in a new light, in as much their variation is far more restricted than previously thought.

3 All analyses were carried out in R version 4.0.3 (R Core Team 2019). Bayesian models were created in the Stan computational framework (http://mc-stan.org/) with the package brms (Bürkner 2017). 
In most contexts, a dative or prepositional phrase agent is all but guaranteed. There is only a handful of situations in which the realization of passive agents can legitimately be characterized as variable.

The remainder of the paper is structured as follows. Section 2 takes up two preliminary questions, including that of whether the dative phrases in example (1) above should be considered agents at all. Section 3 introduces the dataset, variables, and methods used in this study. Section 4 presents a regression analysis of the traditional model of passive agent realization. Section 5 then investigates the expanded model of George (2005). In Section 6, I proffer a new model of passive agent realization based on canonical associations between semantic role and referential prominence (Haspelmath 2021). Model comparison in Section 7 demonstrates that the proposed model is superior to the previous models. Section 8 brings the paper to a close with concluding remarks.

Preliminary issues

The following two questions have been discussed extensively in the literature and therefore need to be addressed before embarking upon the analysis itself:

\section{(4) Preliminary questions}

a. Can the dative case encode the agent semantic role?

b. Should dative participants that co-occur with deontic modal forma-

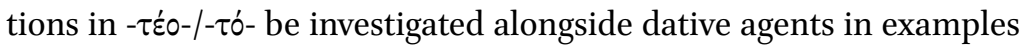
(1) and (3) above?

I discuss each of these questions in turn.

\subsection{The semantic roles of datives in ancient Greek}

Cross-linguistically, the idea of datives as agents may seem prima facie odd, ${ }^{4}$ given that they are often associated with recipients and goals. Greek differs from other archaic Indo-European languages in that its dative is the product of a diachronic syncretism of three earlier cases: the dative, the locative, and the instrumental (Kühner \& Gerth 1898: 404-405; Green 1913: 18-19, 21-23; Petersen 1918a; Petersen 1918b; Luraghi 1987: 362, 365; Calabrese 2008:

4 Agents of passive predicates in Japanese are marked with the dative, but their distribution appears to bear no resemblance to the distribution of dative agents in Greek (see Ishizuka 2012: 120). 
165). As a result, it encodes a wide range of semantic roles, including recipient (Smyth 1956: §§ 1469-1470); possessor (Smyth 1956: §§ 1476-1480); locative (Smyth 1956: §§1530-1538); experiencer (Smyth 1956: §§ 1495-1496, Krüger 2003: § 2.48.4.2D, 2.48.12.2, 2.48.15.2); and benefactive (Smyth 1956: §§14811486). On account of this diversity, scholars have often doubted whether the dative can actually encode the agent semantic role. One common view interprets dative agents as benefactive agents (on which, see Yamashita Smith 2005; Yamashita Smith 2010; Zúñiga \& Kittilä 2010) or as so-called datives of interest (e.g., Kühner \& Gerth 1898: 422; Green 1913: § 90; Smyth 1956: § 1488; George 2005: 78). ${ }^{5}$ Wackernagel (2009: 190) writes that "It [= the dative case, DMG] is not however a form which serves straightforwardly to denote the agent as such, but rather it indicates that the action of the verb is performed in someone's interests." He offers the following example in support of his assertion:

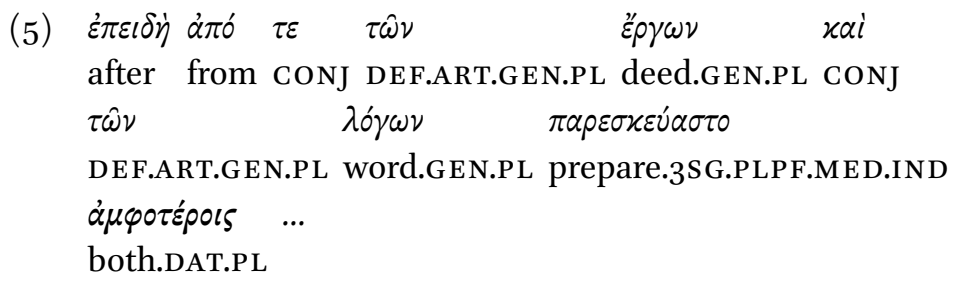

'After arrangements had been made by both sides as to actions and words ...' (Thuc. 4.67.1)

Although the sentence is translated with the passive agent phrase 'by both sides', Wackernagel (2009:19o) argues that ¿ $\mu \varphi \circ \tau$ époı actually means 'for them'. He appears to be suggesting that the dative participant in example (5) is a benefactive agent, that is, the dative participant benefits from the event or its outcome. There are two problems with such a view (cf. Green 1913: §73; Goldstein 2019: 76). The first is that even if the dative participants in examples such as (5) could be shown to be benefactive agents, they would still be agents. The presence of benefactive semantics does not undermine the agent status of the dative participant. The second problem is that it is anything but clear how general such a benefactive sense actually is. It could be the case that Wackernagel's analysis of example (5) is correct, but his claim extends well beyond this

5 Attempts such as these essentially treat dative agents as non-canonical agents. These are participants that are agents but exhibit less agentivity than canonical agents, because they do not meet one or more of the proto-agent properties in Table 1 (see further Yamashita Smith 2005; Kittilä 2005; Ganenkov et al. 2008; Forker 2013). 
passage and amounts to the addition of a phrase such as 'for him/her/them' or 'in his/her/their interest' to all clauses with a dative agent. The data examined in this study do not support such a claim, so I am skeptical of the view that dative agents are at heart benefactive (or malefactive) agents.

Other types of non-canonical agency include involuntary agency, which is illustrated in the following examples from Agul (Lezgic, Caucasian; Ganenkov et al. 2008: 177):
a. baw.a
$n e \bar{k}$
$\bar{a} \bar{t} u z u-n e$

mother.ERG milk.ABS pour.out-PST

'Mother poured out the milk.'
b. baw.a-f-as
ne⿳亠丷厂 ātuzu-ne
mother-AD-ELAT milk.ABS pour.out-PST
'Mother accidentally spilled the milk.'

In example (6a), the ergative argument bawa 'mother' is a canonical agent who acts on her own volition. In example (6b), however, the adelative adjunct bawafas 'mother' is an involuntary participant in the event. There is no evidence to support the view that the classical Greek dative marks attenuated agents of this type. Minimal pairs such as that in example (6) are not attested in Herodotus, for instance (cf. George 2005: 79).

The discussion of how agentive dative participants are has often been conducted in the absence of explicit criteria for agenthood. Table 1 presents the properties of proto-agents and proto-patients proposed by Dowty (1991: 572). Dative agents deserve the status of canonical agents because they routinely fulfill most of the proto-agent criteria (Goldstein 2019: 76-80):
a. $\pi p o \dot{s} \delta \dot{\varepsilon} \quad \tau o \dot{s} \varsigma$

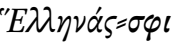
$\sigma x \hat{\eta} \psi \iota \varsigma$
for PTCL DEF.ART.ACC.PL Greek.ACC.PL=3PL.DAT pretext.NOM.SG

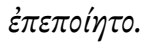

make.3SG.PLPF.MED.IND

'A pretext had been prepared by them for the Greeks.' (Hdt. 7.168.4)

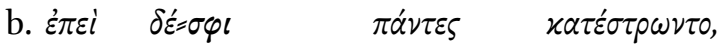

When PTCL=3PL.DAT all.NOM.PL slay.3PL.PLPF.MED.IND

tó ipòv

DEF.ART.ACC.SG sacred.precinct.ACC.SG

$\sigma \nu \lambda \dot{\gamma} \sigma \alpha \nu \tau \varepsilon \varsigma \quad \dot{\varepsilon} \nu \varepsilon \dot{\pi} \rho \rho \eta \alpha \nu$

plunder.PTCP.AOR.ACT.NOM.PL set.fire.to.3PL.AOR.IND.ACT 
TABLE 1 Proto-agent and proto-patient entailments

Proto-agent entailments

Volitional involvement in the event Undergoes change of state or state

Sentience (and/or perception)

Causing an event or change of state in Causally affected by another particianother participant

Stationary relative to movement of another participant

(Exists independently of the event named by the verb)

\section{Proto-patient entailments}

\section{Incremental theme} pant

Movement (relative to the position of another participant)

(Does not exist independently of the event, or not at all)
$\pi \hat{\alpha} \sigma \alpha \nu$
$\tau \dot{\eta} \nu$
áxpó $\pi 0 \lambda \iota v$.
entire.ACC.SG DEF.ART.ACC.SG acropolis.ACC.SG
'When (the suppliants) had all been slain by them, (the Persians) plun- dered the sacred precinct and set fire to the entire acropolis.' (Hdt. 8.53.2)

In example (7a), the agent is sentient, acts on its own volition, and brings about a change of state, namely the creation of an excuse. In example (7b), the dative agent again has the properties of sentience and volition. This time, however, the change that the agent effects in the world is far more forceful than the one in the preceding example. There is nothing about the intentional slaughter of suppliants that suggests attenuated agency.

Finally, dative agents can be used with agent-oriented adverbs (on which, see Piñón 2009; Piñón 2010):

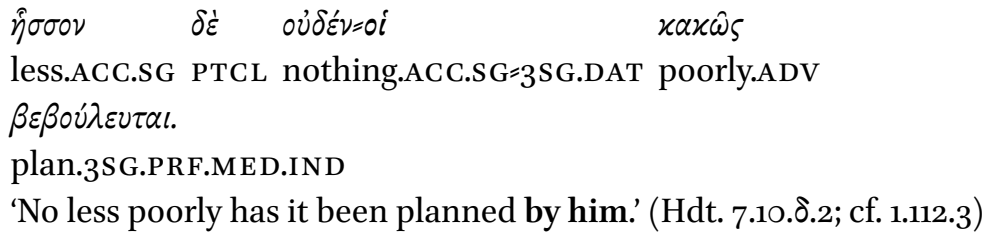

The adverb $x \alpha x \omega ิ \varsigma$ 'poorly' evaluates the success of the event of planning by the pronominal agent. Were this a benefactive dative, it would mean that the dative participant benefited from the event of poor planning. Were it an experiencer dative, it would mean that in the view of the dative participant there 
was an event of poor planning. There is no evidence to support either of these readings.

\subsection{Datives with deontic modals}

In their presentations of dative agents, Jannaris (1897: § 1365) and Smyth (1956: $\S 1488$ ) group the dative agents presented in examples (1) and (3) above with

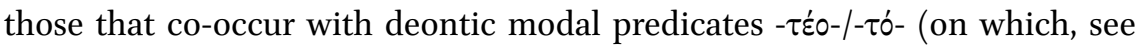
Green 1913: 65-70; Schwyzer 1988: 150.1; Hettrich 1990: 64-67; cf. Ganenkov et al. 2008: 185-186; Forker 2013: 37-38): 6

\section{(9) Deontic modal predicates with dative agent}

$\pi \rho i v \quad \tau \iota \quad \hat{\omega} \nu \quad \mu \dot{\varepsilon} \zeta o \nu$

before INDF.PRO.ACC.SG PTCL greater.ACC.SG

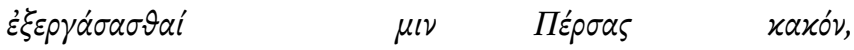

accomplish.INF.AOR.MED 3SG.ACC Persian.ACC.PL harm.ACC.SG

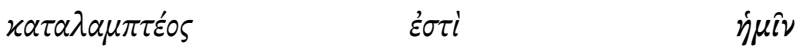

must.be.punished.NOM.SG be.3SG.PRES.IND.ACT 1PL.DAT

$\vartheta \alpha \nu \alpha ́ \tau \omega l$.

death.DAT.SG

'Before (Oroetes) does the Persians greater harm, he must be punished by us with death.' (Hdt. 3.127.3)

The dative pronoun $\dot{\eta} \mu \hat{\imath}$ 'by us' is the locus of an obligation to carry out the event described by the predicate.

There are four reasons why I have not included examples of this type in the present study (Goldstein 2019: 73-74). First and foremost, the dative participants that co-occur with deontic modal predicates never alternate with prepositional phrase agents. In this respect, they differ from the passive agents in

6 Danesi et al. (2017) argue that the deontic construction in examples such as (9) is not a passive, but rather a low-transitivity subconstruction of a more general oblique subject construction. Detailed examination of their claims would take us too far afield, so I will limit myself to a few observations. Danesi et al. (2017) are right about the low transitivity of the predicates in example (9), but this fact in itself does not entail that they lack agents. In addition, it remains to be demonstrated that the dative phrases are actually subjects. Finally, the assertion (Danesi et al. 2017: 148) that deontic modality is not attributable to any specific lexical item in examples such as (9) is at odds with the facts, since the deontic meaning

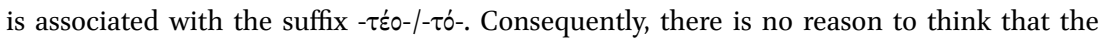
semantics is non-compositional or that modality has to be attributed to the construction as a whole. 
example (1) above. Second, dative participants such as ínî in example (9) differ from canonical agents in that they are subject to an external obligation. As Table 1 shows, volitional involvement in an event is one of the signal properties of agenthood. Third, the dative participant of the modal predicate in example (9) has not actually carried out the event described by the predicate. So in this respect too it is not a true agent. Indeed, the dative participant in examples such as (9) is an experiencer. Finally, the use of the dative in examples such as (9) antedates the development of the Hellenic clade (or dialect continuum), since this use of the dative is also found in Latin and Indo-Iranian:

(10) Deontic modal predicates with dative experiencers

a. Latin

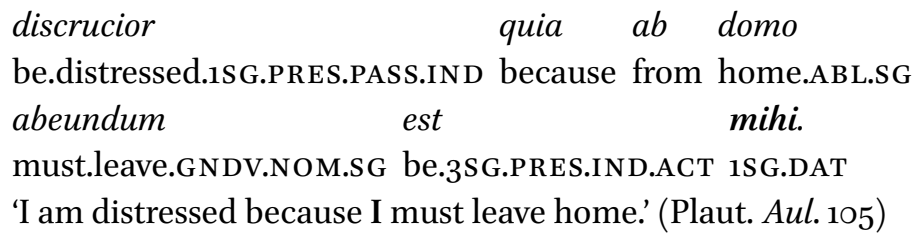

b. Vedic Sanskrit

yá stotíbhyo hávyo

REL.NOM.SG singer.DAT.PL to.be.invoked.NOM.SG

'sti yấman

be.3SG.PRES.IND.ACT sacrifice.LOC.SG

'He who is to be invoked by (the) singers at the sacrifice.' (RV 1.33.2d)

This use of the dative case antedates Greek, but the use of the dative to mark passive agents in the context of perfect predicates is a different matter altogether. Although dative agents with non-modal predicates do show up outside of Greek (e.g., Green 1913; Jamison 1979a; Jamison 1979b), the distributional pattern in example (1) is found in no other archaic Indo-European language. In all likelihood, this pattern is an inner-Greek phenomenon that emerged only after perfects came to be used passively. The distinct diachronic profiles of the two dative constructions in examples (1) and (9) above buttress the point that synchronically these constructions cannot be equated (for more on the diachrony of the Greek dative, see Goldstein 2019: 81-87). 


\section{Data and methods}

\subsection{Corpus}

Previous studies of differential agent marking in Greek have relied on relatively limited samples of data. The present study is the first to investigate the entirety of Herodotus' Histories, a corpus of 188,809 tokens. The analyses in Sections 4-6 below are based on 585 observations of passive predicates with an overt passive agent. ${ }^{7}$ George (2005: 2-19, 91 n. 23) notes that it is sometimes no trivial matter to decide what constitutes a passive predicate. In this section, I highlight a few of the decisions that were made in creating the dataset.

Ancient Greek distinguishes three voices: active, middle, and passive. In the aorist and the future, the active, middle, and passive are inflectionally distinct. Elsewhere, however, the middle and passive are indistinguishable. In the following example, for instance, $\pi \varepsilon i \theta \varepsilon \sigma \theta \alpha$ l can be parsed as a middle infinitive 'obey, comply, believe' or as a passive infinitive 'be persuaded':

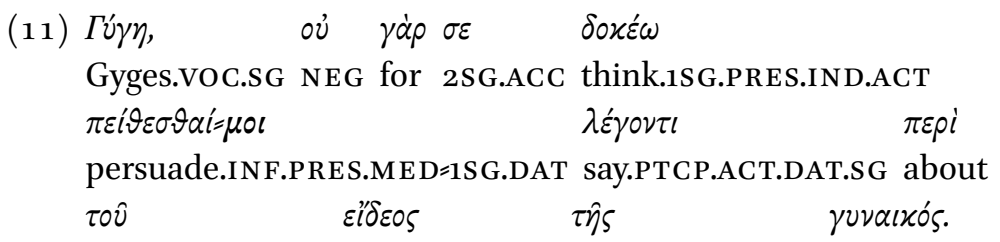

DEF.ART.GEN.SG beauty.GEN.SG DEF.ART.GEN.SG wife.GEN.SG

Middle reading: 'Gyges, I don't think you believe me in what I say about the beauty of my wife.'

Passive reading: 'Gyges, I don't think you are persuaded by me in what I say about the beauty of my wife.' (Hdt. 1.8.2)

The middle reading fits the context better, so this passage is not included in my dataset. In fact, I found no example of $\pi \varepsilon i \theta \varepsilon \sigma \theta \alpha$ in Herodotus with a compelling interpretation as a passive.

A second issue concerns the polysemy of the dative. As noted in Section 2.1 above, the dative can encode a range of semantic roles in Greek, including instrument, experiencer, and agent. As a result, it can be difficult to distinguish agents from instruments, especially when the referent is inanimate. I therefore excluded from consideration as passive agents all inanimate referents (e.g., Hdt. 1.34.2). Even among animate referents the question of instrument versus agent arises:

7 I gratefully acknowledge the critical assistance of Chengzhi Zhang, Silvio Curtis, and especially Anahita Hoose in coding the data. 


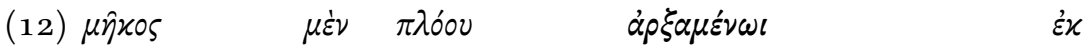
length.ACC.SG PTCL voyage.GEN.SG begin.PTCP.FUT.ACT.DAT.SG from $\mu \nu \chi 0 \hat{} \quad \delta เ \varepsilon \varkappa \pi \lambda \omega \hat{\omega} \sigma \alpha l \quad \dot{\varepsilon} \zeta \quad \tau \dot{\eta} \nu$ inland.creek.GEN.SG sail.out.from.INF.AOR.ACT into DEF.ART.ACC.SG

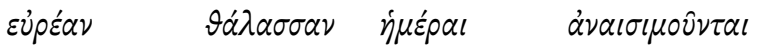
wide.ACC.SG sea.ACC.SG day.NOM.PL spend.3PL.PRES.MED.IND

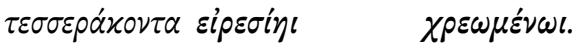
forty rowing.DAT.SG use.PTCP.PRES.MED.DAT.SG Dative agent reading: 'As for the length of the journey, forty days are consumed by one beginning to sail on a ship with oars from an inland creek into the wide sea.'

Dative experiencer reading: 'As for the length of the journey, for one beginning to sail on a ship with oars from an inland creek into the wide sea forty days are consumed.' (Hdt. 2.11.2)

In both translations, the predicate $\alpha \nu \alpha \iota \sigma \iota \mu o v v \tau \alpha$ l is interpreted passively as 'be consumed'. The difference between them lies in the interpretation of the boldface dative noun phrase. In the first translation, it is interpreted as a passive agent, 'by one beginning to sail on a ship with oars'. In the second, it is interpreted as an experiencer dative, 'for one beginning to sail on a ship with oars'. I follow the latter interpretation, because the dative participant does not control the length of the journey. Examples such as this one are accordingly not included in the dataset.

Conjoined predicates occurring with a single passive agent were treated as two observations if the agent was interpreted with both predicates:
(13) ... $\varepsilon \sigma \sigma \omega^{\prime} \vartheta \eta \alpha \nu$
iं $\pi \dot{0} \tau \hat{\omega} \nu$
$\Phi \omega \varkappa \varepsilon ́ \omega \nu$
defeat.3PL.AOR.PASS.IND by DEF.ART.GEN.PL Phocaean.GEN.PL

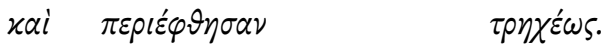
CONJ handle.3PL.AOR.PASS.IND roughly.ADV
'... They were defeated by the Phocaeans and treated roughly.' (Hdt. 8.27.2)

Since the phrase $\dot{\pi} \pi \dot{\partial} \tau \hat{\omega} \nu \Phi \omega x \varepsilon \dot{\varepsilon} \omega \nu$ 'by the Phocaeans' is the agent of both $\dot{\varepsilon} \sigma \sigma \dot{\omega}-$ $\theta \eta \sigma \alpha \nu$ 'were defeated' and $\pi \varepsilon \rho \varepsilon \varepsilon \varphi \theta \eta \sigma \alpha \nu$ 'were handled', this example is listed in the dataset as though the agent phrase occurred once with each predicate.

Finally, morphologically active verbs that are semantically passive and cooccur with an overt dative or prepositional phrase agent are included in the dataset (George 2005: 7 n. 16): 


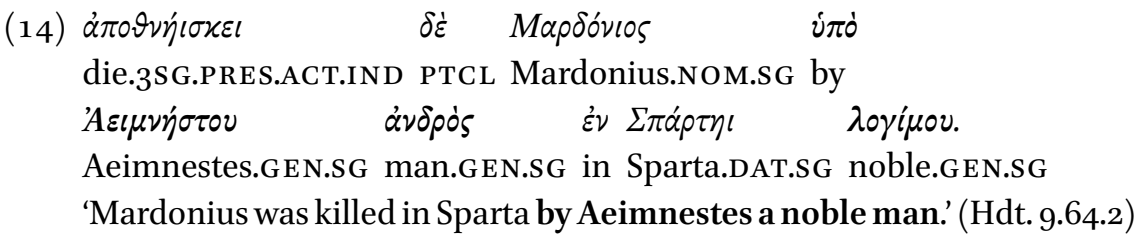

Despite the active morphology of $\dot{\alpha} \pi \circ \theta v \dot{\eta} \mid \sigma x \varepsilon l$, it has a passive interpretation

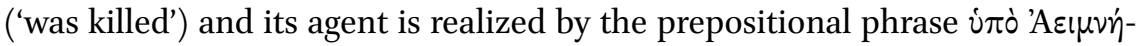

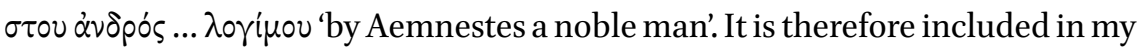
dataset. Other examples of this kind include $\dot{\alpha} \lambda$ óv$_{\tau} \alpha$ 'having been taken captive' at Hdt. 8.105.1 and $\dot{\alpha} \pi \circ \theta \alpha \nu \varepsilon i v$ 'was killed' at Hdt. 9.75.1.

\subsection{Bayesian statistics and regression modeling}

One of the central claims of this paper is that differential agent marking in Herodotus is conditioned not by a single factor, but by a constellation of factors. To evaluate the contribution of various determinants to the realization of passive agents, I use Bayesian mixed-effects logistic regression, which is currently considered the gold standard in corpus linguistics (Barth \& Kapatsinski 2018: 100)..$^{8}$ Logistic regression models the probability of a dichotomous response variable as a function of one or more predictor variables. In this study, the response variable is the passive agent phrase, that is, whether it occurs in the dative case or as a prepositional phrase. The predictor variables are introduced in Table 2.

Logistic regression models without random effects assume that every observation is independent, an assumption that the data under investigation violate. Indeed, most corpus data violate this assumption (cf. George 2005: 88; Gries 2015: 99, 111). In my dataset, for instance, many of the observed passive agent phrases co-occur with the same verbal predicate. To handle this dependency, there is an intercept for each of the 197 unique predicates in the dataset. These varying intercepts also allow for the possibility of lexically specific effects in the realization of passive agents. ${ }^{9}$

The basic idea behind Bayesian inference is to evaluate how much evidence there is for a hypothesis given the observable data (Nicenboim \& Vasishth 2016: 592). The probability of a hypothesis is calculated with Bayes' Theorem:

$$
p(\theta \mid y)=\frac{p(y \mid \theta) \cdot p(\theta)}{p(y)}
$$

8 For more on logistic regression, see Agresti 2013.

9 Analyses with both varying intercepts and varying slopes were also carried out, but these did not perform as well as the models with only varying intercepts. 
Bayes' Theorem enables us to calculate the probability of an unobserved parameter $\theta$ (such as a regression coefficient) given a set of observed data $y$. $p(\theta \mid y)$ is known as the posterior probability and is calculated by multiplying the likelihood of the data $p(y \mid \theta)$ by its prior probability $p(\theta)$ and then dividing by the marginal likelihood $p(y)$. A $t$-distribution with three degrees of freedom, a location of $\mathrm{o}$, and a scale parameter of 2.5 was used as the prior distribution for the regression coefficients. In most real-world applications of Bayes' Theorem, the posterior probability cannot be computed analytically. To circumvent this issue, I use Markov Chain Monte Carlo (MCMC) methods to sample from the posterior distribution. For each analysis in Sections 4 through 6, six chains were run for twenty thousand generations each with a burn-in of four thousand generations. Convergence was confirmed by visual autopsy of the MCMC traces.

\subsection{Factors investigated}

The variables investigated in this study are presented in Table 2. Each row presents a factor along with its levels (with reference levels listed first). The first variable, agent realization, is the dependent variable and registers the realization of a passive agent phrase with a dative case or a prepositional phrase. All prepositional phrase agents were included and not simply those headed by i $\pi$ o. $^{10}$ Variables two through six are the predictor variables. For variable two, the grammatical aspect of each passive verbal predicate with an overt agent expression was recorded as either perfect or non-perfect (a category that encompasses imperfectives and perfectives). Variable three registers patient animacy: inanimate patients were coded as INANIMATE and participants higher on the agency hierarchy were coded as ANIMATE. Variables four and five refer to the morphological and prosodic status of the agent phrase. Variable four registers the nominality of the agent, with its two levels distinguishing personal pronouns and nominal agents. In variable five, nominality and prosody are entwined. The following levels are used: NON.P RONOMINAL (for an agent that is a not a personal pronoun), STRESSED.PRO (for a passive agent that is a stressed personal pronoun), and ENCLITIC.PRO (for a passive agent that is an enclitic personal pronoun). Since variables four and five overlap, they do not co-occur in the models below. Variable six distinguishes participial and non-participial passive predicates, which encompass finite, infinitive, and periphrastic verb forms.

10 For an investigation of the differences between the various prepositions among prepositional phrase agents, see George 2005: 103-211. 


\begin{tabular}{llll}
\hline Number & Factor & Levels & Status \\
\hline 1 & Agent phrase & PP, DATIVE & Dependent \\
2 & Perfect aspect & NON.PERFECT, PERFECT & $\begin{array}{l}\text { Independent } \\
\text { Independent }\end{array}$ \\
3 & Patient animacy & ANIMATE, INANIMATE & Independent \\
4 & Agent nominality & PRONOUN, NOUN & Independent \\
5 & Agent nominality & NON.PRONOMINAL, STRESSED.PRO, & \\
& and prosody & ENCLITIC.PRO & Independent \\
\hline
\end{tabular}

\section{$4 \quad$ The traditional model}

As discussed above in Section 1, it has long been known that perfect aspect is an important factor in the realization of passive agents. The semantics of the Greek perfect are notoriously complex (e.g., Wackernagel 1904; Chantraine 1927; Haspelmath 1992; Haug 2008; Bentein 2014). A full treatment of its semantics would take us too far afield, so I will limit myself to highlighting one particular reading of the perfect passive, the resultative. Resultative readings of the Greek perfect exhibit two signal properties. First, they entail a past event of the type denoted by the predicate. Second, the resultant state of the event holds at reference time (i.e., the time used to determine whether the proposition is true or false). The following pair of examples illustrates these properties:

(15) Resultative perfects

a. $\omega_{\varsigma}=\sigma \varphi l \quad \tau \dot{\alpha} \quad \beta \varepsilon ́ \lambda \varepsilon \alpha$

when=3PL.DAT DEF.ART.NOM.PL arrow.NOM.PL

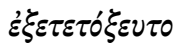

shoot.off.3SG.PLPF.MED.IND

'When the arrows had been shot off by them ...' (Hdt. 1.214.2)

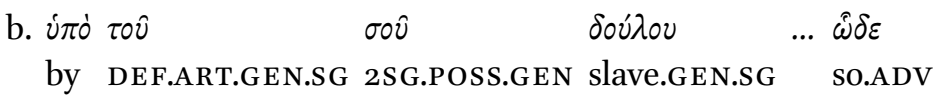
$\pi \varepsilon \rho \iota \mathcal{\beta \rho i \sigma} \mu \varepsilon \vartheta \alpha$.

insult.1PL.PRF.MED.IND

'We have been so insulted by your slave.' (Hdt. 1.114.5) 


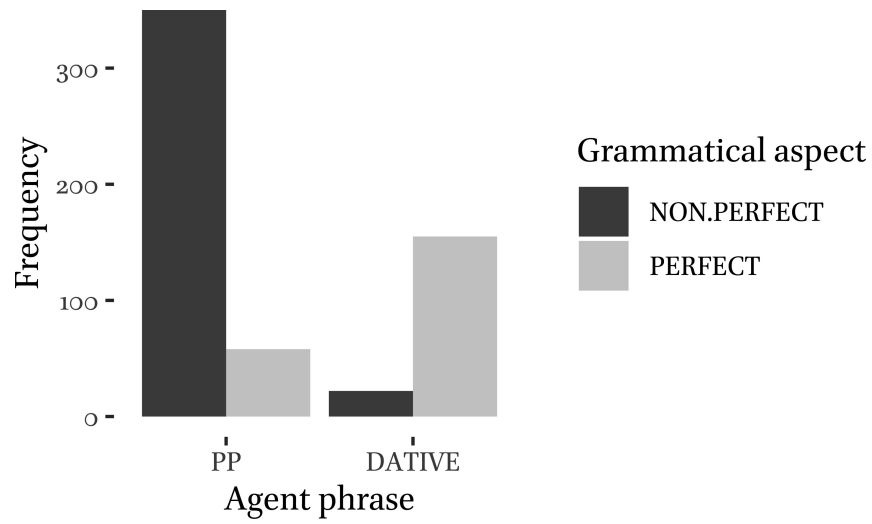

FIGURE 4 Grammatical aspect and passive agent expression

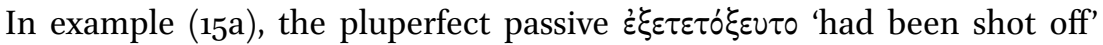
entails not only past events of shooting arrows, but also that the arrows are gone at the reference time of the narrative. Likewise, in example (15b), the perfect passive $\pi \varepsilon p \iota \sim \beta p i \sigma \mu \varepsilon \theta \alpha$ 'we have been insulted' entails that the subject is insulted at the time of the utterance as the result of a past insult. In both examples, the patient undergoes a change of state, a property that is common among perfect passives cross-linguistically. In fact, Comrie (1976: 86) writes that "The perfect passive is precisely that form which predicates a change of state to the object of an action." This is an important point and one that I will return to in Section 6.5 below. Figure 4 presents the frequency distribution of passive agent realization according to grammatical aspect. This distribution makes clear the motivation for the traditional analysis, since perfect predicates co-occur far more often with dative agents than non-perfect predicates (i.e., imperfective or perfective predicates).

\subsection{Regression analysis}

To test the traditional model, a Bayesian mixed-effects logistic regression analysis was carried out in which the dependent variable was the realization of the passive agent phrase and the sole predictor variable was perfect aspect. The estimates of this model are summarized in Table 3, which presents the mean, standard error (SE), and lower and upper bounds of the $95 \%$ credible interval (CI) of the posterior distribution for each parameter. The estimate for the intercept is the log odds of a dative agent given the reference level of the predictor variables. In this model, the only predictor variable is grammatical aspect and its reference level is non-perfect (i.e., imperfective or perfective) aspect. The estimated coefficients, which are also in log odds, measure the effect that each 
Agent phrase $\sim$ Perfect $+(1 \mid$ Predicate $)$

Term

Estimate SE CI-low CI-high

\section{Fixed effects}

Intercept

Perfect Aspect

$\begin{array}{rrrr}-5.16 & 0.68 & -6.61 & -3.97 \\ 6.05 & 0.69 & 4.82 & 7.5^{2}\end{array}$

\section{Random effects}

Predicates $(\mathrm{n}=197)$

Standard deviation of varying intercepts

ICC

$\begin{array}{lll}3.58 & 0.64 & 2.48\end{array}$

4.98

fixed effect has on the expression of the passive agent phrase compared to its reference level.

The positive value for the estimate of perfect aspect means that this property increases the probability of a dative agent. The $95 \%$ credible interval for this estimate is $\left(4.82,7.5^{2}\right)$, so we can be $95 \%$ confident that the true value of the parameter lies within this range. The negative value of the intercept indicates that prepositional phrase agents are predicted on average when the predicate is not a perfect passive.

Log odds are difficult to interpret directly, so we can instead use the predicted probabilities of the model to understand the strength of the predictor variables. Figure 5 presents box plots of the predicted probabilities of the traditional model according to grammatical aspect. (Jitter is added to the graphs to reveal the quantity of observations with the same predicted probability.) When the passive predicate is perfect, the median predicted probability of a dative agent is well above 0.75 , but when the passive predicate is not perfect, it plummets to less than o.1. The results of the regression analysis thus agree with the traditional account in as much there is a strong association between perfect aspect and dative agents.

The standard deviation of the varying intercepts reflects the amount of variability among the intercepts for lexical items. ${ }^{11}$ The intra-class correlation

11 There does not appear to be any correlation between the value of the intercept and the semantics of the verb. Plots with the values of the varying intercepts can be found in the supplementary files. 


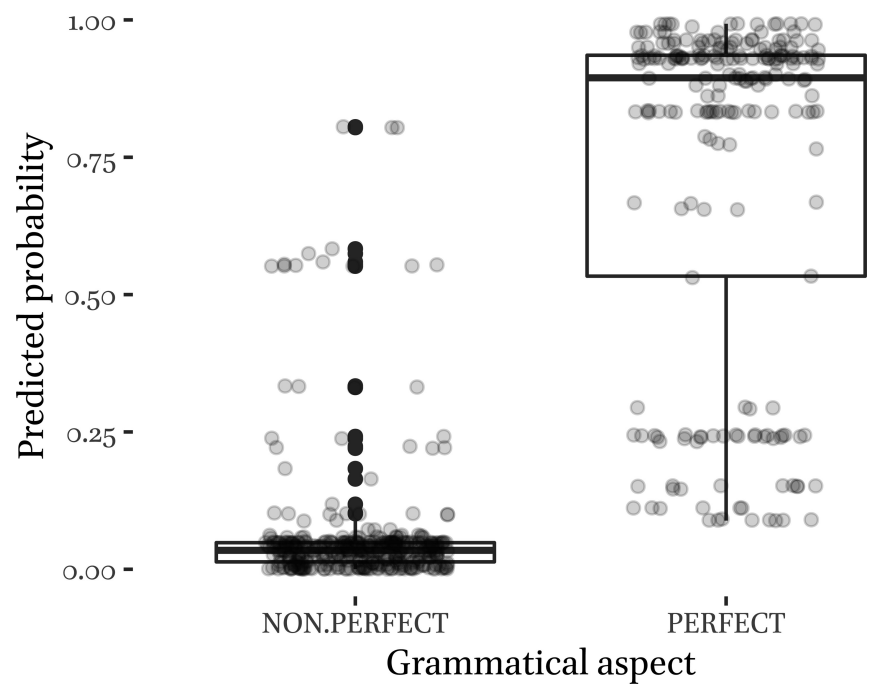

FIGURE 5 The predicted probabilities of dative agents according to the traditional model

coefficient (ICC) is often used to interpret this variation. The ICC measures how homogeneous the realization of agent phrases is for each lexical item and ranges in value from zero to one. An ICC of zero would mean that passive agent realization does not depend on lexeme at all. An ICC of one would entail that for each predicate the realization of passive agents was uniform. The ICC of the traditional model is $0.8 .^{12}$ Such a high ICC value suggests that passive agent realization is strongly correlated within each lexeme. The ICC is so high at least in part because more than half of the predicates in the dataset (106 out of 197, to be exact) only occur once and therefore exhibit no variation.

\subsection{Problems with the traditional model}

The traditional account predicts that dative agents co-occur with perfect predicates and that prepositional phrase agents do not. The distribution in Figure 4 makes the empirical inadequacy of this analysis manifest. Although most dative agents do indeed co-occur with perfect predicates, there is no shortage of prepositional phrase agents that co-occur with perfect predicates (as illustrated by example 3a above). In short, perfect aspect is an important factor in the realization of passive agents, but it is not the sole determinant. The models presented in Sections 5 and 6 acknowledge the importance of gram-

12 The ICC of the null model (i.e., a model with no predictor variables) is o.84. 
matical aspect, but at the same time contend that differential agent marking in Herodotus is more complex than the traditional account allows.

In the most detailed and sophisticated analysis of passive agents in Greek to date, George (2005) argues for the importance of three further factors beside grammatical aspect: the animacy of the patient, the nominality of the agent, and the morphology of the passive predicate. Dative agents are said to correlate with perfect passive predicates, inanimate patients, pronominal agents, and non-participial verb forms (George 2005: 87, 91). Prepositional phrase agents by contrast are associated with non-perfect predicates, inanimate subjects, nonpronominal agents, and participial verb forms. ${ }^{13}$

George subscribes to the view that the primary function of argument marking is to discriminate among arguments (cf. Comrie 1978: 379-380; Moravcsik 1978; Comrie 1989: 124-127; Aissen 2003: 437). According to this view, certain arguments require less marking in some contexts and more marking in others. George maintains that animacy plays a crucial role in determining when an argument requires more or less marking. Animacy categories are ranked according to the following scale (cf. Silverstein 1976; Dixon 1979: 85-91; Kiparsky 2008):

\section{(16) Animacy hierarchy}

1st Person Pronoun, 2nd Person Pronoun $>$ 3rd Person Pronoun $>$ Proper Noun/Kinship Term $>$ Human Noun $>$ Animate Noun $>$ Inanimate Noun

Participants with the highest animacy are at the left end of the scale, those with the lowest at the right. Higher animacy correlates with a greater likelihood of being the agent of a predicate; e.g., a personal pronoun is more likely to bear the agent role than an inanimate noun.

13 The reader should be aware that this is strictly speaking not what George (2005: 87) claims about the distribution of prepositional phrase agents. His claim is restricted to prepositional phrase agents headed by i $\pi^{\prime}$ with perfect predicates, but on p. 88 he seems to suggest that such agent phrases pattern with prepositional phrase agents that co-occur with non-perfect predicates. George (2005: 88-90) also argues that adjectival and substantivized participles correlate with different realizations of passive agents. This is not a distinction that I recorded in my dataset. So the regression analysis presented in Section 5.1 below includes the main factors that George identifies as important for the realization of passive agents, but it does not encompass his whole account of differential agent marking (e.g., the disambiguating use of prepositional phrase agents has not been considered). 
If two participants of a passive predicate are animate and inanimate, it is a priori clear that the animate participant will be the agent and a "relatively ambiguous agent marker like the dative is sufficient" (George 2005: 87):

(17) Dative agent with inanimate patient
a. $\dot{\varepsilon} \pi \varepsilon i \tau \varepsilon \delta \dot{\varepsilon}=0 i$ óṕ́puxto
after PTCL=3SG.DAT dig.3SG.PLPF.MED.IND
'After (the trench) had been dug by her ...' (Hdt. 1.185.5)
b. $\ddot{\omega} \varsigma=\sigma \varphi l \quad \tau \dot{\alpha} \quad \beta \varepsilon \dot{\lambda} \varepsilon \alpha$
when=3PL.DAT DEF.ART.NOM.PL arrow.NOM.PL

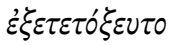
shoot.off.3SG.PLPF.MED.IND
'When the arrows had all been shot off by by them ...' (Hdt. 1.214.2)

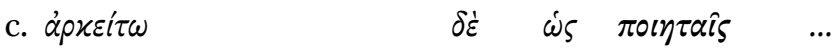
suffice.3SG.PRES.ACT.IMPV PTCL that poet.DAT.PL
Eïp $\tau$ qal
say.3SG.PRF.MED.IND
'Let it suffice that it has been said by poets ...' (Thuc. 6.2.1)

In each of these examples, the patient is inanimate and the agent human. The latter is realized as a dative agent, precisely as George's account predicts.

When the agent and the patient are both animate, however, they "have equal potential to be the agent" (George 2005:87). A prepositional phrase is therefore required to disambiguate their roles:

(18) Prepositional phrase agent with animate patient
a. $\varepsilon^{\prime} \xi \varepsilon \lambda \eta \lambda a \mu \varepsilon \dot{\varepsilon} 0 \varsigma$ $\tau \varepsilon \quad$ i $\pi \dot{o} \tau 0 \hat{v}$
banish.PTCP.PRF.MED.NOM.SG CONJ by DEF.ART.GEN.SG
$\pi \alpha \tau \rho \dot{s} s$
father.GEN.SG
'And having been banished by my father, I ...' (Hdt. 1.35.3)

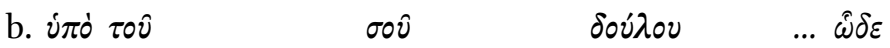
by DEF.ART.GEN.SG 2SG.POSS.GEN slave.GEN.SG SO.ADV $\pi \varepsilon p \imath \beta \beta i \sigma \mu \varepsilon \vartheta \alpha$.
insult.1PL.PRF.MED.IND
'We have been so insulted by your slave.' (Hdt. 1.114.5)




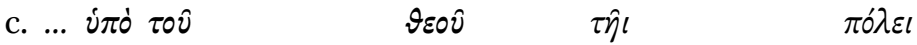
by DEF.ART.GEN.SG god.GEN.SG DEF.ART.DAT.SG city.DAT.SG $\delta \varepsilon \delta \delta ́ \sigma \vartheta \alpha \iota$.
give.INF.PRF.MED
'... [I happen] to have been given to the city by god.' (Pl. Ap. 31a8)

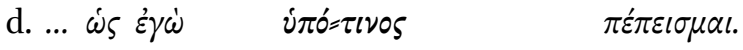
as 1SG.NOM by=INDF.PRO.GEN.SG persuade.1SG.PRF.MED.IND
'... as I have been persuaded by someone.' (Pl. Phaed. 108c8)

In a similar vein, George (2005: $\left.85^{-86}\right)$ claims that prepositional phrase agents are also used to avoid the morphosyntactic ambiguity that a dative agent would have introduced:

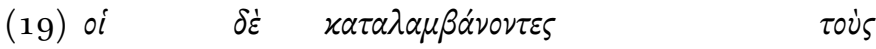

3PL.NOM PTCL overtake.PTCP.PRES.ACT.NOM.PL DEF.ART.ACC.PL

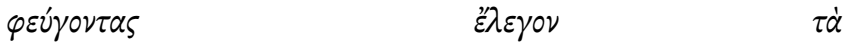

fugitive.PTCP.PRES.ACT.ACC.PL tell.3PL.IMPF.ACT.IND DEF.ART.ACC.PL

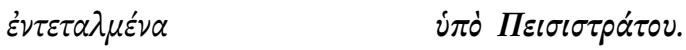

order.PTCP.PRF.MED.ACC.PL by Peisistratos.GEN.SG

'They overtook the fugitives and told them what had been ordered by Peisistratus.' (Hdt. 1.63.2)

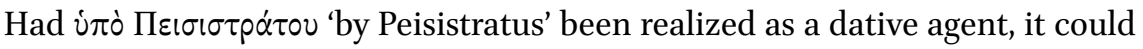
have been interpreted as the recipient argument of $\tau \dot{\alpha} \varepsilon \dot{\nu} \tau \varepsilon \tau \alpha \lambda \mu \varepsilon \dot{v} \alpha$, i.e., 'what had been issued as an order to Peisistratus'. According to George, a prepositional phrase was used here to avoid this ambiguity.

\subsection{Regression analysis}

To test George's model, a Bayesian mixed-effects logistic regression analysis was carried out in which the dependent variable was the realization of the passive agent phrase and the predictor variables were the following: perfect aspect, the nominality of the agent, the animacy of the patient, and the morphology of the predicate. The estimates of this model are summarized in Table 4. Figure 6 presents box plots of the predicted probabilities for each of the factors in the model.

Three aspects of the results stand out. First, perfect aspect still holds pride of place as the strongest determinant of agent realization. Second, agent nominality and patient animacy have a clear effect on the realization of passive agent phrases. Note, however, in Figure 6 that animate patients have a stronger 
Agent phrase $\sim$ Perfect aspect + Patient animacy + Agent nominality + Predicate morphology $+(1 \mid$ Predicate $)$

Term

\section{Fixed effects}

Intercept

Perfect Aspect

Pronominal Agent

Inanimate Patient

Participial predicate
Estimate SE CI-low CI-high

$\begin{array}{rrrr}-8.29 & 1.57 & -11.85 & -5.75 \\ 5.68 & 0.99 & 4.02 & 7.87 \\ 4.09 & 0.87 & 2.64 & 6.04 \\ 3.20 & 0.97 & 1.53 & 5.31 \\ -1.20 & 0.64 & -2.48 & 0.03\end{array}$

\section{Random effects}

Predicates $(n=197)$

Standard deviation of varying intercepts

ICC

$3 \cdot 75$

2.29

$5 \cdot 75$

0.81

effect on agent realization than inanimate patients. The discovery of the importance of agent nominality and patient animacy is the main achievement of George's study and below I adopt them in my own model. Third, the $95 \%$ credible interval for participial predicates includes zero, so this factor may well have no impact on the realization of passive agents. Furthermore, the median predicted probabilities of dative agents in Figure 6 are low for both participial and non-participial predicates. ${ }^{14}$

\subsection{Problems with George's account}

George's analysis suffers from three substantial problems. First, his claim that differential agent marking is motivated by the disambiguation of participant roles is contradicted by the evidence. Consider, for instance, the following examples:

14 The variance inflation factor (VIF) for each predictor variable in George's model was calculated with the R package performance (Lüdecke et al. 2021). It was below 5 in each case, which means that the correlation of the predictors is low. 


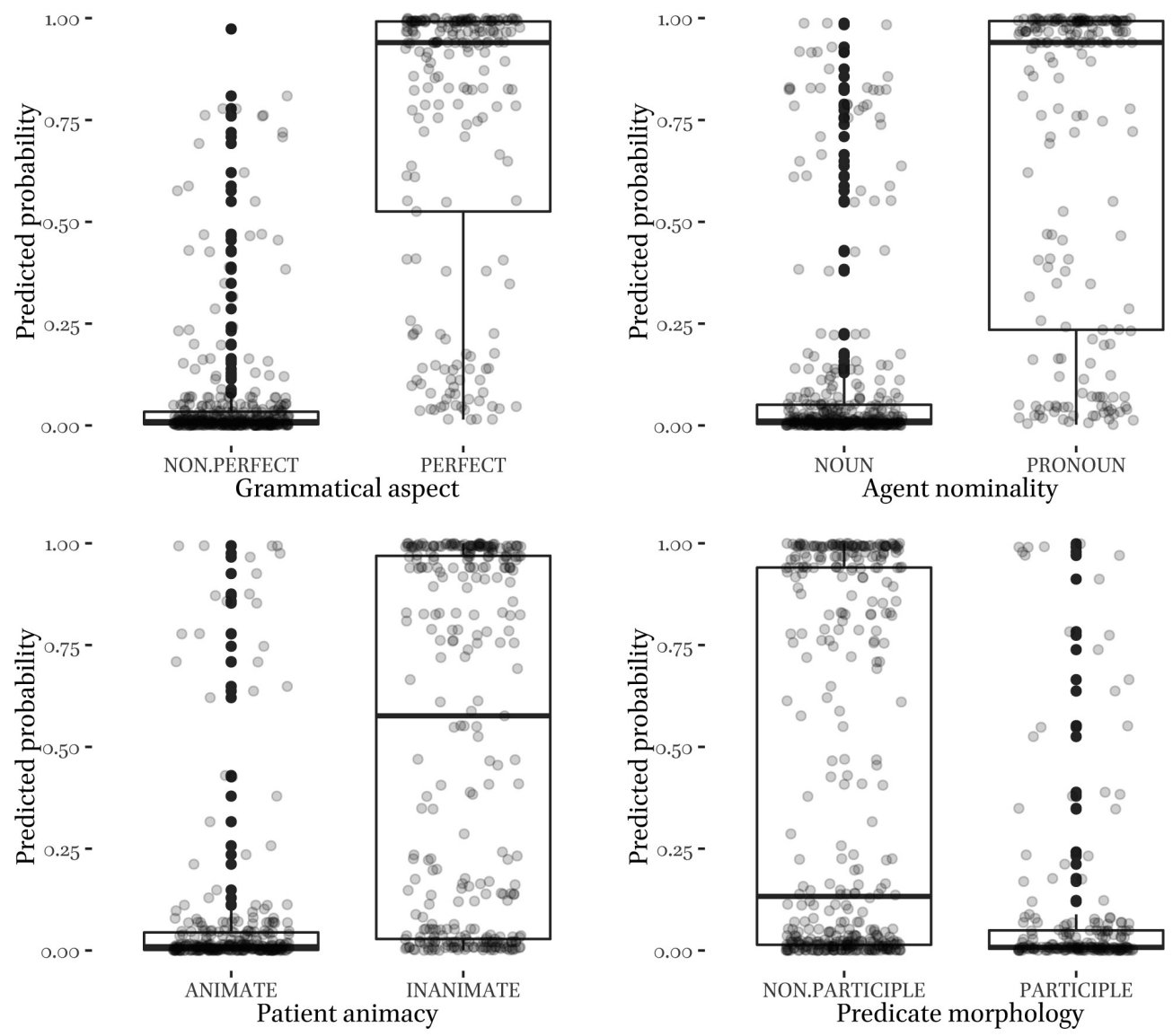

FIGURE 6 The predicted probabilities of dative agents according to the model of George 2005

(20) Inanimate patients with prepositional phrase agents

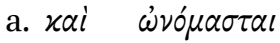 i $\pi \dot{\partial} \tau \hat{\omega} \nu$
CONJ name.3SG.PRF.MED.IND by DEF.ART.GEN.PL

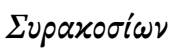

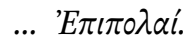
Syracusan.GEN.PL Epipolai

'And it has been named Epipolai by the Syracusans.' (Thuc. 6.96.2)

b. $\dot{\xi} \xi \quad \hat{\omega} \nu \quad \delta i \eta ́ p \pi \alpha \sigma \tau 0 \quad i \pi \dot{\delta} \tau 0 \hat{v}$

from REL.GEN.PL plunder.3SG.PLPF.MED.IND by DEF.ART.GEN.SG

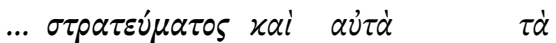

army.GEN.SG ADD self.NOM.PL DEF.ART.NOM.PL $\xi \dot{\lambda} \lambda \alpha$.

wood.NOM.PL 
'From which even the wood itself had been plundered by the army.' (Xen. An. 2.2.16)

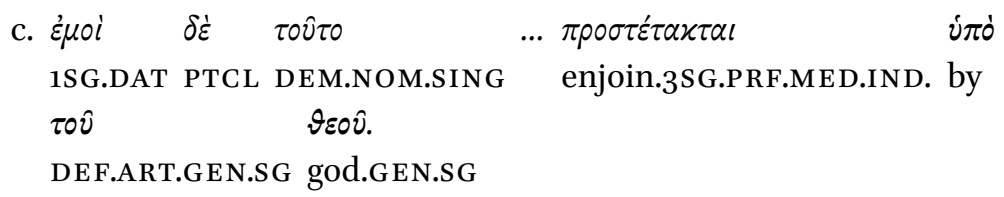

In each case, the patient of the passive predicate is inanimate and the agent animate. This is precisely the context in which George's analysis predicts a dative agent, since the differences in animacy should leave no doubt as to which participant is the agent.

If Greek were as sensitive to the potential ambiguity of dative noun phrases as George claims, it is hard to understand how an example such as the following - with two dative noun phrases - was possible:

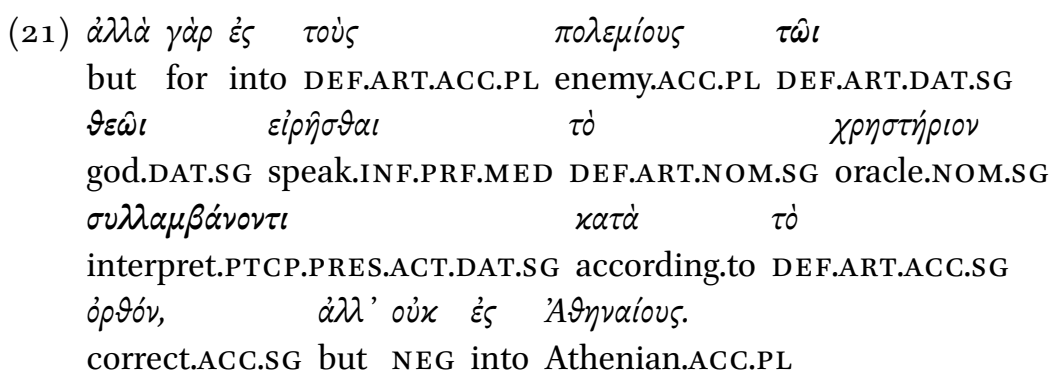

'For one interpreting (the oracle) correctly, it has been spoken by god not in regard to the Athenians, but in regard to their enemies.' (Hdt. $7.143 .2)$

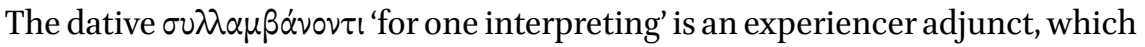
co-occurs with the dative agent $\tau \hat{\omega} \iota \varepsilon \varepsilon \hat{\omega} \iota$ 'the god'. George's account predicts that a prepositional phrase agent would have been used here to clarify the semantic roles of the dative noun phrases.

A second problem is that certain aspects of George's analysis lack motivation. For instance, he argues on p. 87 that dative agents preponderate in clauses with pronominal agents and inanimate patients because there is no need for the disambiguating force of a prepositional phrase agent in such a context. But why are prepositional phrase agents regarded as unequivocal markers of agency in the first place? Given that íó can also encode other semantic roles, it is unclear why it has this privileged status. 
Finally, the motivation that George offers for the factors in his analysis lacks coherence. Patient animacy and agent nominality correlate with dative agents because they provide cues to the semantic roles of the participants, but why should perfect passive predicates be associated with dative agents? George's account seems to entail that in this context there is less of a need to disambiguate the agent phrase (since the dative is alleged to be a relatively ambiguous marker of agency), but why this should be the case is anything but clear. In fact, George does not pursue this line of analysis, but instead claims that the motivation for the association between perfect aspect and dative agents is a historical artifact (p. 102): "The anomalous use of the dative of agent with the perfect first arose because the perfect expressed a state rather than an action." I have argued elsewhere that this claim is untenable (Goldstein 2019: 84-87), but my point here is less about the motivation for the association between perfect aspect and dative agents and more about the relationships among the factors that George argues for. Differential agent marking in Greek cannot simply be a matter of participant-role disambiguation, since that alone does not account for the association between dative agents and perfect passive predicates.

A new approach

\subsection{Canonical role-reference associations}

In this section, I present a new analysis of differential agent marking that not only achieves better empirical coverage but also provides coherent motivation for the grammatical factors that influence the realization of passive agents. The point of departure for my analysis is the insight that differential argument marking is conditioned by the relationship between semantic role and referential prominence (e.g., Bossong 1985; Bossong 1991; Aissen 2003). Haspelmath (2021: 7) identifies the following associations for agents and patients:

\section{(22) Single-argument association tendencies}

a. Agents tend to be referentially prominent.

b. Patients tend to be referentially non-prominent.

Referential prominence encompasses a range of properties including animacy, definiteness, and person. (This topic is discussed in greater detail in the next section.) According to the following two universals, deviations from the usual associations of role rank and referential prominence result in more grammatical coding: 
(23) The role-reference association universal (Haspelmath 2021:3) Deviations from the usual associations of role rank and referential prominence tend to be coded by longer grammatical forms if the coding is asymmetric.

(24) The single-argument flagging universal (Haspelmath 2021: 9) If a language has an asymmetric single-argument flagging split depending on some prominence scale, then the coding is longer for prominent patient/theme-arguments or for non-prominent agent/recipientarguments.

The passive agent alternation in Herodotus illustrates both of these universals. Referentially prominent agents and referentially non-prominent patients favor dative agents. By contrast, referentially non-prominent agents and prominent patients favor prepositional phrase agents. Passive agent phrases that deviate from the usual associations of semantic role and referential prominence thus receive more coding, in as much as they are marked with both case and a preposition.

\subsection{Referential prominence}

The crucial question for my account is what constitutes referential prominence. Haspelmath (2021: $\left.5^{-6}\right)$ himself identifies two broad categories of prominence, inherent prominence and discourse prominence. To inherent prominence belong properties such as the following:

\section{(25) Inherent prominence}

a. Person scale

Locuphoric (1st/2nd person) > Aliophoric (3rd person)

b. Nominality scale

Person Form (independent or index) $>$ Full Nominal

c. Animacy scale

Human $>$ Animate $>$ Inanimate

These are all properties that do not depend on context. By contrast, discourse prominence does depend on context:

(26) Discourse prominence

a. Definiteness scale

Definite $>$ Specific Indefinite $>$ Indefinite Nonspecific

b. Givenness scale

Discourse-Given $>$ Discourse-New 
TABLE 5 The properties that favor prepositional phrase and dative agents in the proposed model

Factor

Dative agent Prepositional phrase agent

$\begin{array}{lll}\text { Agent Nominality and Prosody } & \text { Enclitic Pronoun } & \text { Nominal } \\ \text { Patient Animacy } & \text { Inanimate } & \text { Animate } \\ \text { Grammatical Aspect } & \text { Perfect } & \text { Imperfective, Perfective }\end{array}$

\section{c. Focus scale}

Background $>$ Focus

Differential agent marking in Herodotus differs from other examples of differential marking in the literature in that it is not conditioned by a single grammatical factor (such as animacy or definiteness). There is instead a constellation of factors that contribute to the realization of passive agent phrases, which are presented in Table 5. Grammatical properties favoring dative agents are listed in the column Dative agent; those favoring prepositional phrase agents are listed in the column Prepositional phrase agent. The properties that favor dative agents all involve referentially prominent agents and referentially nonprominent patients, whereas prepositional phrase agents are found in contexts that deviate from these associations. In the following sections, I elaborate on each of the factors in Table 5 .

\subsection{Agent nominality and prosody}

As noted in example $(25 \mathrm{~b})$ above, agent nominality is an important component of role-reference associations. Agents are canonically associated with a person form, whether a pronoun or an index. The frequency distributions in Figure 7 make it clear that dative agents in Herodotus are usually pronominal while prepositional phrase agents are predominantly nominal.

If we look more closely, however, we see that it is not only the nominality of the agent phrase that matters, but also its prosodic realization. Most personal pronouns in Herodotus could be realized as stressed or enclitic. (The full inventory of pronouns in Herodotus is presented in Table 11 in the Appendix.) Figure 8 presents the distribution of passive agent phrases according to whether the agent is an enclitic pronoun, stressed pronoun, or noun. Enclitic pronouns are with only one exception restricted to dative agents.

The following examples illustrate the association between dative agents and enclitic pronouns: 


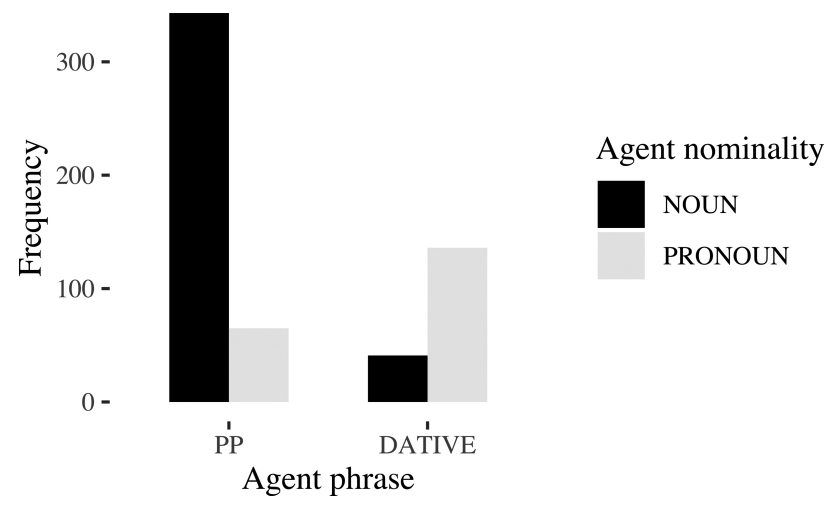

FIGURE 7 Nominality and passive agent expression

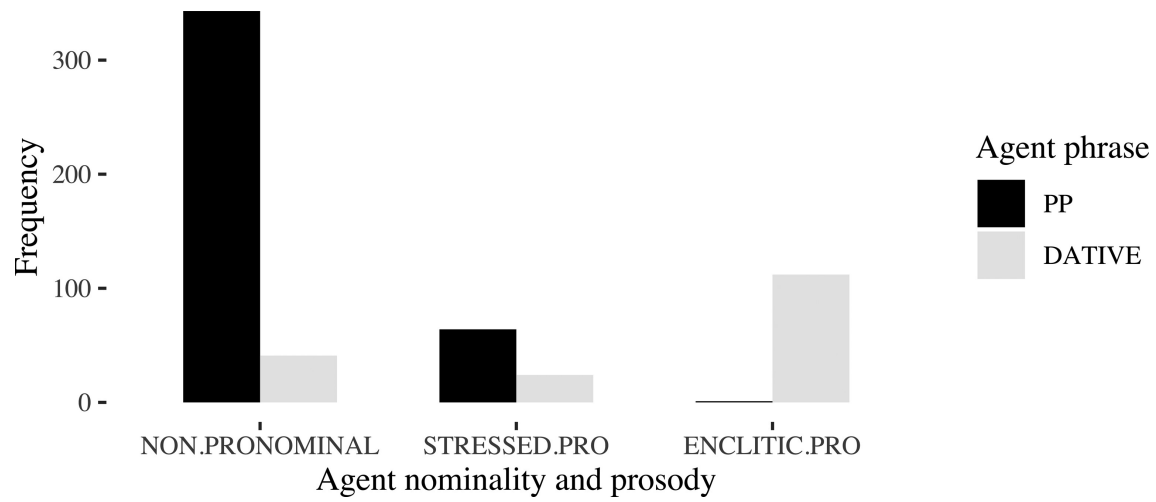

FIGURE 8 Nominality, prosodic phonology, and passive agent expression

(27) Dative pronominal enclitic agents
a. $\hat{\omega}$ $\xi \varepsilon \hat{\varepsilon} \varepsilon$

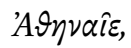
$\dot{\eta}$
$\delta^{\prime}$

voc.PTCL guest.voc.sG Athenian.voc.sg Def.ART.NOM.SG PTCL

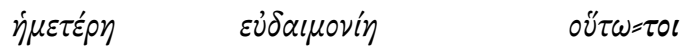

1SG.POSS.NOM good.fortune.NOM.SG So.ADV=2SG.DAT

$\dot{\alpha} \pi \dot{\varepsilon} \rho \rho l \pi \tau a l \quad \dot{\varepsilon} \varsigma \quad \tau \dot{0}$

value.at.nothing.3SG.PRF.MED.IND into DEF.ART.ACC.SG

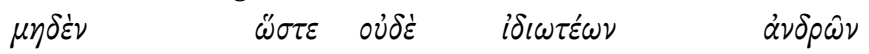

nothing.ACC.SG COMP not.even common.GEN.PL man.GEN.PL

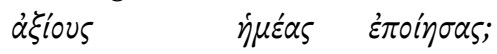

worthy.ACC.PL 1PL.ACC consider.2SG.AOR.ACT.IND

'Athenian guest, has our good fortune been so valued by you at nothing that you consider us worthy not even of commoners?' (Hdt. 1.32.1) 
b. $\tau \alpha \hat{v} \tau \alpha \quad \mu \dot{\varepsilon} \nu \quad \tau \dot{\alpha}$

DEM.NOM.PL PTCL DEF.ART.NOM.PL

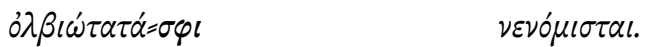

most.fortunate.NOM.PL=3SG.DAT deem.3SG.PRF.MED.IND

'This has been deemed the most fortunate (fate) by them.' (Hdt. 1.216.3; cf. 1.138.2)

The following examples illustrate the association between prepositional phrase agents and stressed pronominal and nominal agents:

(28) Stressed pronominal prepositional phrase agent

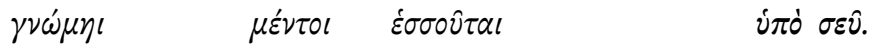

counsel.DAT.SG however best.3SG.PRES.MED.IND by 2SG.GEN

'In counsel, however, he is bested by you.' (Hdt. 7.237.1)

(29) Nominal prepositional phrase agents

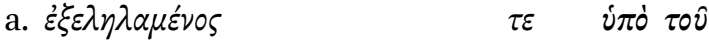
banish.PTCP.PRF.MED.NOM.SG CONJ by DEF.ART.GEN.SG

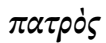
father.GEN.SG
'And having been banished by my father, I ...' (Hdt. 1.35.3; cf. 1.168.1, $1.173 \cdot 3$ )

b. $\dot{\omega} \varsigma \quad \delta \dot{\varepsilon} \quad \ddot{\omega} \rho \alpha \quad \pi \dot{\alpha} \nu \tau \alpha \quad \mu \dot{\varepsilon}$

when PTCL see.3SG.IMPF.ACT.IND whole.ACC.SG PTCL

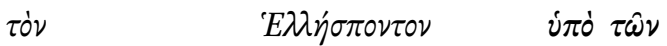

DEF.ART.ACC.sG Hellespont.ACC.SG by DEF.ART.GEN.PL

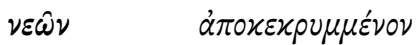

ship.GEN.PL cover.PTCP.PRF.MED.ACC.SG

'When he saw that the whole Hellespont had been covered by the ships ...' (Hdt. 7.45.1)

Monosyllabic enclitic pronouns generally do not occur as complements of prepositions (Powell 1938: 340; Goldstein 2016: 82 n. 2), because prepositions are themselves thought to be proclitic and in a proclitic-enclitic sequence there is no prosodic host. To circumvent this situation, when a personal pronoun is the complement of a preposition, it is typically stressed. In my dataset, the following example is the only exception to this generalization: 


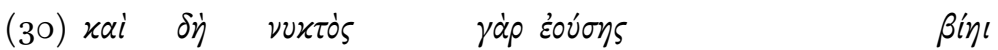

CONJ PTCL night.GEN.SG for be.PTCP.PRES.ACT.GEN.SG force.DAT.SG

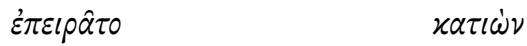

attempt.3SG.IMPF.MED.IND enter.PTCP.PRES.ACT.NOM.SG

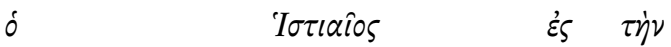

DEF.ART.NOM.SG Histiaeus.NOM.SG into DEF.ART.ACC.SG

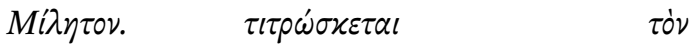

Miletos.ACC.SG wound.3SG.PRES.MED.IND DEF.ART.ACC.SG

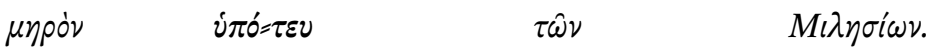

thigh.ACC.SG by=INDF.PRO.GEN.SG DEF.ART.GEN.PL Milesian.GEN.PL 'And when it was night Histiaeus attempted to force his way into Miletos. He was wounded in the thigh by one of the Milesians.' (Hdt. 6.5.2)

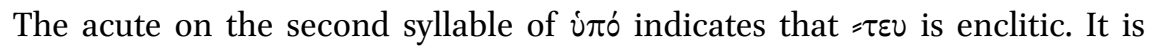
unclear how such an example was possible prosodically, but I suspect that the presence of $\tau \hat{\omega} \nu \mathrm{M} \iota \lambda \eta \sigma^{\prime} \omega \nu$ 'of the Milesians' somehow enables the enclitic pronoun to appear after the preposition.

There may also be pragmatic motivation for the near absence of pronominal enclitics among prepositional phrase agents. In addition to being prosodically deficient, enclitic pronouns are also referentially prominent. In fact, they are the zenith of the accessibility hierarchy:

(31) Accessibility hierarchy (Ariel 1990: 73)

Enclitic Pronoun $>$ Unstressed Pronoun $>$ Stressed Pronoun $>$ Proximal Demonstrative $>$ Distal Demonstrative $>$ First Name $>$ Last Name $>$ Definite Description

Enclitic pronominal agents are thus referentially prominent on three scales: nominality, definiteness, and accessibility. The strong correlation between enclitic pronominal agents and dative-marking is thus entirely expected given the scales in examples (25) and (26) above. ${ }^{15}$

\subsection{Patient animacy}

Just as agents are usually high in animacy, patients typically occupy the lower regions of the animacy scale. In Herodotus, inanimate patients preponderate among dative agents:

15 Whether there are any stressed pronouns that are "underlyingly" enclitic is an open question. That is, there may be pronouns that are stressed only because they serve as the complement of a preposition. 
(32) Inanimate patient with dative agents

a. $\varepsilon^{\prime} \xi \varepsilon \mu \pi 0 \lambda \eta \mu \varepsilon \dot{\varepsilon} \nu \nu=\sigma \varphi l$ $\sigma \chi \varepsilon \delta \dot{\nu} \nu \quad \pi \dot{\alpha} \nu \tau \omega \nu \quad \ldots$ sell.off.PTCP.PRF.MED.GEN.PL=3PL.DAT almost all.GEN.PL 'Once everything had almost been sold off by them ...' (Hdt. 1.1.3)

b. $\ddot{\omega} \varsigma=\sigma \varphi l \quad \tau \dot{\alpha} \quad \beta \varepsilon \dot{\lambda} \varepsilon \alpha$

when=3PL.DAT DEF.ART.NOM.PL arrow.NOM.PL

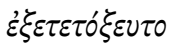
shoot.off.3SG.PLPF.MED.IND 'When the arrows had been shot off by them ...' (Hdt. 1.214.2)

c. $\dot{\eta}$ $\mu \dot{\varepsilon} \nu \quad \delta \dot{\eta} \quad$ ő $\psi \varsigma \varsigma \quad \tau 0 \hat{v}$ DEF.ART.NOM.SG PTCL PTCL vision.NOM.SG DEF.ART.GEN.SG

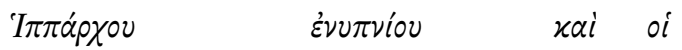
Hipparchus.gen.sg in.sleep.GEN.SG CONJ DEF.ART.NOM.PL

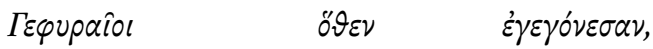
Gephyraian.NOM.PL from.where originate.3PL.PLPF.ACT.IND

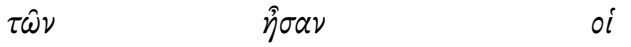

DEF.ART.GEN.PL be.3PL.IMPF.ACT.IND DEF.ART.NOM.PL

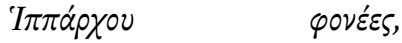

Hipparchus.GEN.SG murderer.NOM.PL $\alpha \dot{n} \eta \dot{\gamma} \eta \tau \alpha i=\mu \circ$. relay.3SG.PRF.MED.IND=1SG.DAT 'The dream of Hipparchus and where the Gephyraians originated, to which clan his murderers belonged, have already been relayed by me.' (Hdt. 5.62.1)

By contrast, prepositional phrase agents are more common with animate patients:

(33) Animate patients with prepositional phrase agents

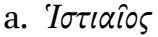 $\mu \varepsilon \mu \varepsilon \tau$ นर́vos i $\pi \dot{0}$
Histiaeus.NOM.SG release.PTCP.PRF.MED.NOM.SG by

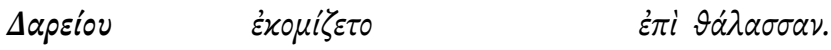 Dareius.GEN.SG travel.3sG.IMPF.MED.IND to sea.ACC.SG 'Histiaeus, having been released by Dareius, was traveling to the sea.' (Hdt. 5.108.1) 


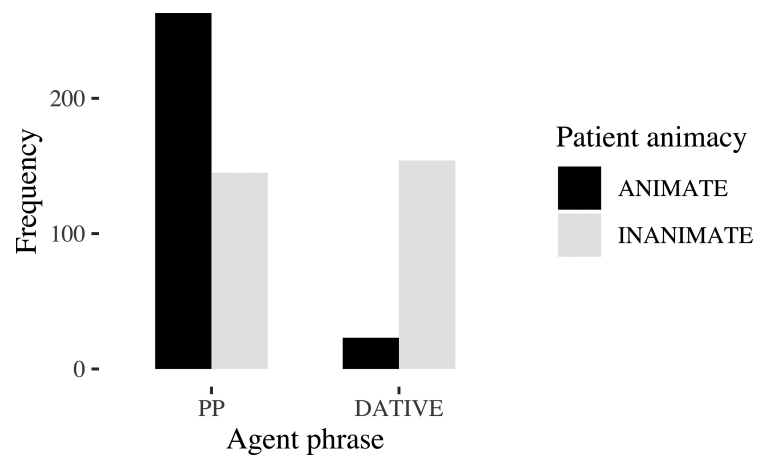

FIGURE 9 Patient animacy and passive agent expression

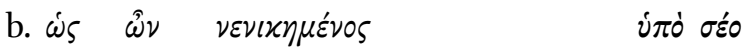

thus PTCL win.PTCP.PRF.MED.NOM.SG by 2SG.GEN $\mu \varepsilon \tau \alpha \gamma \iota \nu \omega \sigma \kappa \omega$.

change.one's.mind.1SG.PRES.ACT.IND

'Having thus been won over by you I have changed my mind.' (Hdt. 1.40.1)

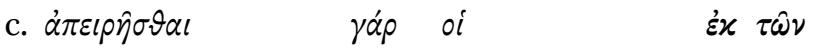

forbid.INF.PRF.MED PTCL DEF.ART.NOM.PL by DEF.ART.GEN.PL

$\gamma \varepsilon i \nu \alpha \mu \varepsilon \dot{v} \omega \nu \quad \mu \eta \delta \varepsilon v i \quad \dot{\varepsilon} \pi l \delta \varepsilon i x \nu \dot{v} v a l$.

parent.GEN.PL no.one.DAT.SG show.INF.PRES.ACT

'For she had been forbidden by the (child's) parents to show it to anyone.' (Hdt. 6.61.4)

The frequency distribution of dative and prepositional phrase agents according to the animacy of the patient is presented in Figure 9. Inanimate patients cooccur with dative and prepositional phrase agents in roughly equal numbers, but the vast majority of animate patients are found among the latter.

\subsection{Grammatical aspect}

Cross-linguistically, animacy and nominality are well known for their roles in differential marking, but grammatical aspect is a less prominent conditioning factor (for examples, see Kiparsky 1998; Malchukov \& Hoop 2011; Malchukov 2015). Although the importance of perfect aspect for the passive agent alternation in Greek has long been clear, the reason why this factor is so important has remained elusive. On my account, dative agents predominate among perfect passive predicates because the semantic role and referential prominence of the patient subject are aligned in this context. Recall from Section 4 above that the 
resultative is the most prominent reading of the classical Greek perfect and that resultative passive perfects predicate a change of state to the patient (Comrie 1976: 86). Undergoing a change of state is in fact one of the proto-patient properties in Table 1 above (Section 2.1). As such, the patient subject of a perfect passive is not referentially prominent, which aligns it with its semantic role.

The effect of perfect passive predicates on the realization of passive agents accords with the tense-aspect-mood scale proposed by Andrej Malchukov for analyzing alignment splits:

(34) TAM-hierarchy for alignment splits (Malchukov \& Hoop 2011: 44, Malchukov 2015: 285)

Imperative $>$ Future $>$ Present/Imperfective $>$ Past Perfective $>$ Perfect $>$ Resultative

As we move rightward along the scale, the patient is more affected by the event and therefore less referentially prominent. The two rightmost categories are associated with the Greek perfect passive and these are precisely the ones that favor dative agents in Herodotus.

\subsection{Regression analysis}

To test the proposed model, a Bayesian mixed-effects logistic regression analysis was carried out in which the dependent variable was the realization of the passive agent phrase and the predictor variables were the following: perfect aspect, the nominality and prosody of the agent, and the animacy of the patient. The estimates for the proposed model are presented in Table 6 and the predicted probabilities in Figure 10.

The most striking result is the estimated coefficient for enclitic pronouns, which is massive. Indeed, its impact is more potent than any other factor, including perfect aspect. Regression analysis thus upends the traditional view that perfect aspect is the most important determinant of passive agent realization. Interestingly, with the inclusion of prosody, agent pronominality itself is probably not an important factor (as the credible interval for stressed pronominal agents includes o). ${ }^{16}$

16 The variance inflation factor (VIF) for each predictor variable in the proposed model was below 5 , which means that the correlation of the predictors is low. 
TABLE 6 Estimated coefficients of the proposed model

Agent phrase $\sim$ Perfect aspect + Patient animacy + Agent nominality-prosody $+(1 \mid$ Predicate $)$

Term

Estimate SE CI-low CI-high

Fixed effects

Intercept

Perfect Aspect

$\begin{array}{llll}-10.10 & 2.08 & -14.90 & -6.78\end{array}$

Stressed Pronominal Agent

$\begin{array}{llll}6.49 & 1.28 & 4.38 & 9.38\end{array}$

Enclitic Pronominal Agent

$\begin{array}{llll}1.36 & 0.93 & -0.35 & 3.32\end{array}$

Inanimate Patient

$\begin{array}{rrrr}15.78 & 4.71 & 8.83 & 27.04 \\ 3.60 & 1.28 & 1.42 & 6.46\end{array}$

\section{Random effects}

Predicates $(\mathrm{n}=197)$

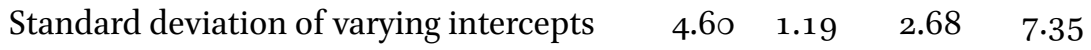

ICC

$$
0.87
$$

\subsection{Original counterexamples}

We can now take a second look at the exceptions to the traditional analysis in example (3) from section 1 above to see how the proposed model handles them:

(35) Counterexamples

a. PP-agent with perfect

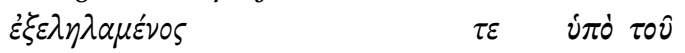

banish.PTCP.PRF.MED.NOM.SG CONJ by DEF.ART.GEN.SG

$\pi \alpha \tau \rho o \dot{s}$

father.GEN.SG

'And having been banished by my father, I ...' (Hdt. 1.35.3)

b. Dative agent with non-perfect (perfective)

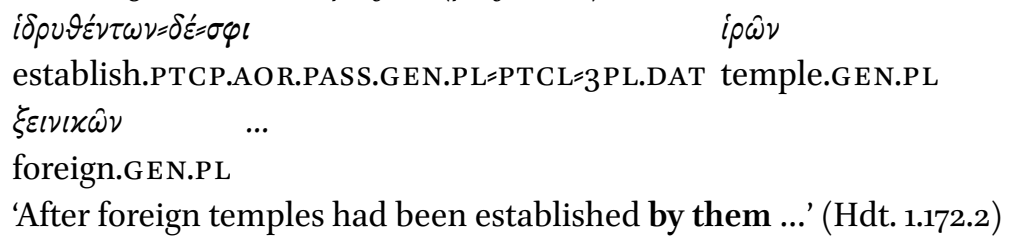



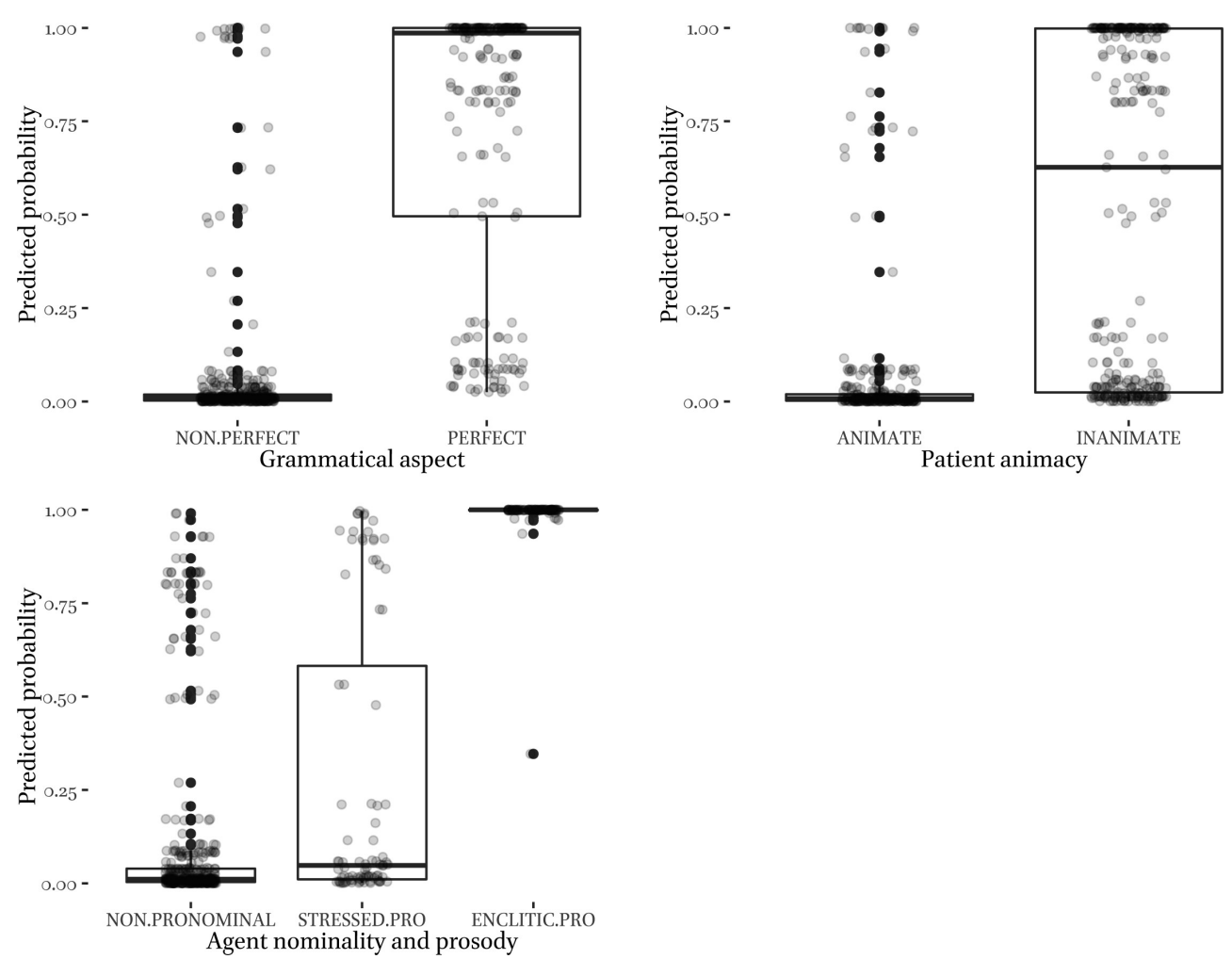

FIGURE 10 The predicted probabilities of dative agents according to the proposed model

Although the participle is in the perfect in example (35a), the patient is human and the agent is non-pronominal, both of which lower the probability of a dative agent. In fact, the predicted probability of a dative agent in this example is 0.081 . Likewise, in example (35b), although the participle is an aorist, the agent is pronominal and the patient is inanimate. The proposed model estimates the probability of a dative agent in this example at o.99. With a multifactorial account of agent realization such as the one presented here, dative agents are predicted even in the absence of a perfect passive predicate.

\subsection{The loci of variation}

Differential agent marking emerges in a new light under the proposed model, in that the variation between dative and prepositional phrase agents turns out to be highly constrained. Figure 11 presents the predicted probabilities of a dative agent according to each constellation of clausal properties in the proposed model. For most combinations, the predicted probabilities of a dative agent 


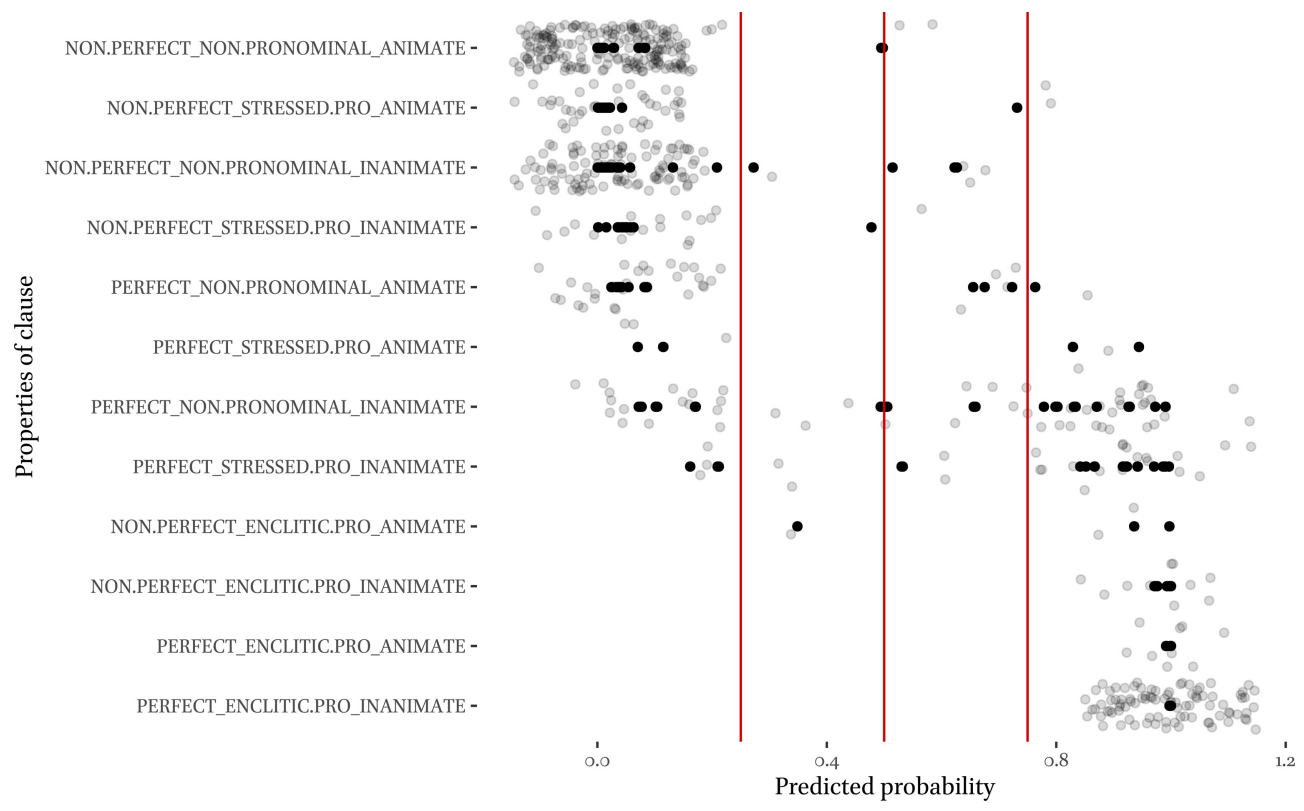

FIGURE 11 Predicted probability of a dative agent according to clausal properties

are either well below twenty-five percent or well above seventy-five percent (the vertical lines mark $25 \%, 50 \%$, and $75 \%$ predicted probabilities). It is only in a restricted set of contexts that they exhibit more variation. (There is more than one predicted probability in most contexts because the model allows passive agent realization to be influenced by the idiosyncrasies of individual predicates.) In particular, the predicted probabilities for clauses with a perfect predicate, non-pronominal agent, and inanimate patient and for clauses with a perfect predicate, stressed pronominal agent, and inanimate patient exhibit more spread.

The recognition that variation in passive agent marking is restricted to certain contexts is important for two reasons. First, it suggests a new approach to the diachronic development of passive agent realization in Greek. After Herodotus, dative agents gradually become less frequent until they eventually disappear altogether. If the predicted probabilities of agent realization in Figure 11 approximate the grammar of classical Greek speakers, then it is possible that the clausal configurations characterized by more spread in predicted probabilities served as an entry point to the disappearance of the passive agent alternation. The intercepts of each of the models in Sections 4 through 6 show that Herodotean Greek is biased toward prepositional phrase agents. So it may have been the case that the distribution of prepositional phrases was extended 
first into the clausal contexts characterized by more variability in their predicted probabilities, since it is here that neither form of passive agent would have had a strong foothold. Examination of this possible diachronic development unfortunately lies beyond the remit of the current study. For the moment the point is simply that the model proposed here identifies potential contexts for change that previous studies have not. ${ }^{17}$

Second, the recognition of restricted variation suggests that the differential marking characterized as "optional" in some languages may not be so free. Aissen (2003) reports a number of languages in which differential object marking is obligatory in some contexts and "optional" in others, including Old Spanish (Aissen 2003: 462-465), Hindi (Aissen 2003: 466-468), and Persian (Aissen 2003: 468-471). McGregor (2009: 493-497), McGregor \& Verstraete (2010), and McGregor (2010) also discuss optional ergative marking. More detailed investigation among these languages may reveal a restricted "optionality" similar to what we find in Herodotus.

\section{7}

\section{Model comparison}

In this section, I assess the performance of the models presented in Sections 4 through 6 above with posterior predictive checks, correct classification rates, Bayes factors, and marginal and conditional $R^{2}$ values. The proposed model outperforms the other two on all diagnostics.

\subsection{Posterior predictive check}

In a posterior predictive check, datasets are generated from the posterior distribution and then compared to the distribution of the original dataset. The results of the posterior predictive checks are presented in Figure 12. The bold curves represent the original datasets and the ribbons embracing them the replicated datasets. The observed and predicted values for each model are similar, so on the whole they fit the data well. Compared to the traditional model, however, the ribbon of simulated data is slightly narrower in the model of George (2005) and the proposed model, which is an indication of superior fit.

17 George (2005: 94-101) argues that it was the decline of the perfect passive that led to the demise of differential agent marking. 

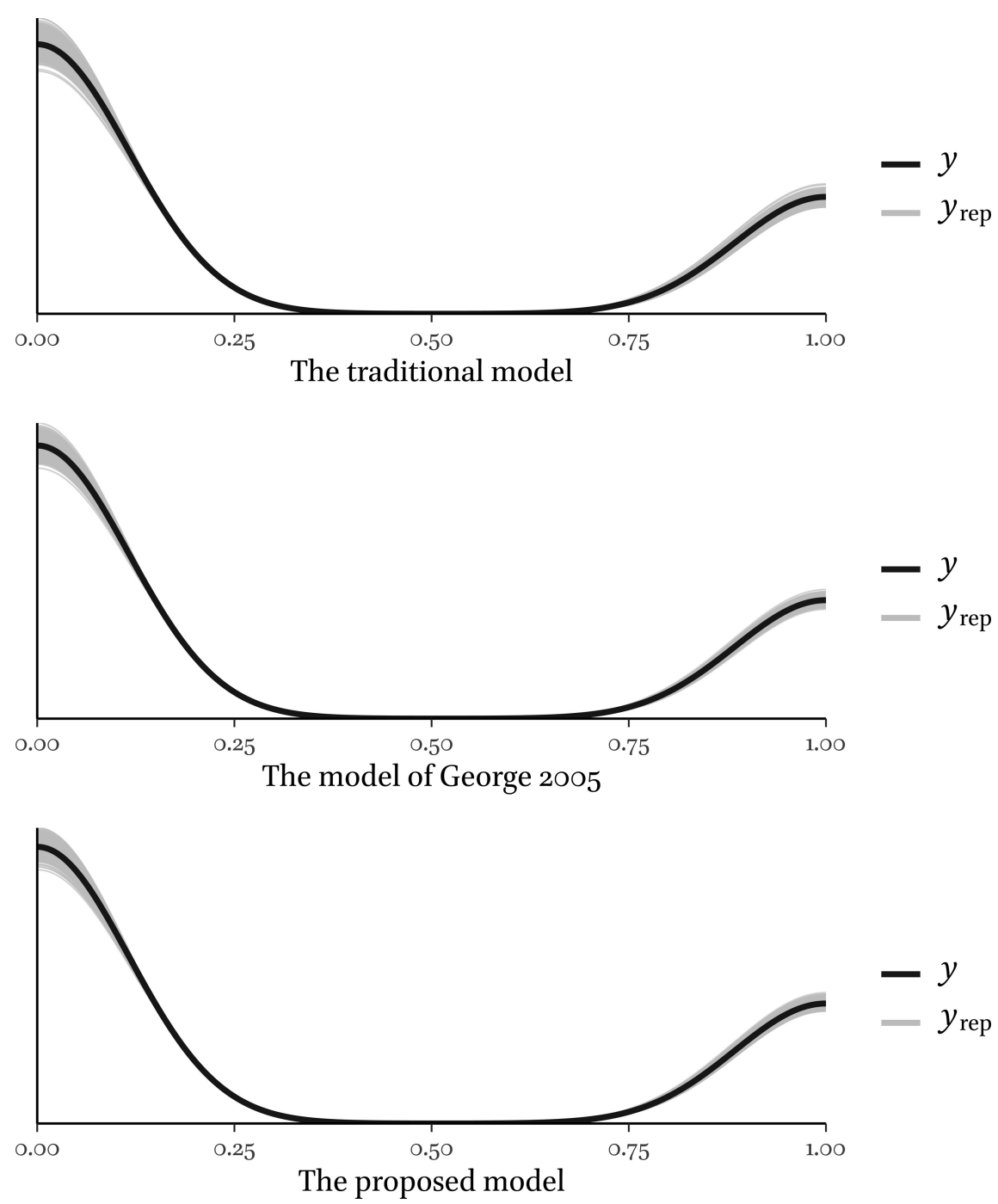

FIGURE 12 Posterior predictive checks

\subsection{Correct classification rate}

The correct classification rate (CCR) measures how accurately each model predicts the realization of the agent for unseen data. For this diagnostic, seventy percent of the observations (409 examples) were randomly sampled and used as training data. The remaining thirty percent (176 examples) were then used as test data. The correct classification rates reported in Table 7 measure how well the models classified the test data. If the model assigned a probability of at least 0.5 to the true realization of the passive 
TABLE 7 Comparison of the correct

classification rates $(\mathrm{CCR})$

Model CCR

Traditional model $\quad 0.87$

George $2005 \quad 0.9$

Proposed model $\quad 0.92$

agent, that was considered a success. If, however, the true agent realization was not predicted with at least 0.5 probability, that was considered an error.

The CCR of the traditional model is 0.87 . In other words, a model with the sole factor of perfect aspect correctly classifies 87 percent of the observations in the test data. The correct classification rate is good even for the traditional model, which is no doubt one reason why some researchers have considered this the only conditioning factor of passive agent realization. The proposed model achieves better empirical coverage than either the traditional account or that of George 2005, however.

In the following examples from the test data, the proposed model failed to predict the correct realization of the agent phrase:

(36) Prepositional phrase agent predicted
a. 'Hpodótov

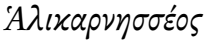
iotopins

Herodotus.GEN.SG Halicarnassian.GEN.SG investigation.GEN.SG

$\dot{\alpha} \pi \dot{\delta} \delta \varepsilon \xi \iota \varsigma \quad \ddot{\gamma} \delta \varepsilon, \quad \dot{\omega} \varsigma \quad \mu \dot{\eta} \tau \varepsilon$

presentation.NOM.SG DEM.NOM.SG COMP NEG.CONJ

$\tau \dot{\alpha} \quad \gamma \varepsilon \nu o ́ \mu \varepsilon v \alpha$

DEF.ART.NOM.PL happen.PTCP.AOR.MED.NOM.PL from

$\dot{\alpha} \nu \vartheta \rho \omega \dot{\omega} \pi \nu \nu \quad \tau \hat{\omega} \iota \quad \chi \rho o ́ v \omega l \quad \grave{\xi} \xi i \tau \eta \lambda \alpha$

people.GEN.PL DEF.ART.DAT.SG time.DAT.SG extinguished.NOM.PL

$\gamma \dot{\varepsilon} \nu \eta \tau \alpha l, \quad \mu \dot{\eta} \tau \varepsilon \quad \varepsilon^{\prime} \rho \gamma \alpha \quad \mu \varepsilon \gamma \alpha \dot{\lambda} \lambda \alpha$

become.3SG.AOR.SBJV.MED NEG.CONJ work.NOM.PL great.NOM.PL

$\tau \varepsilon \quad$ xai $\vartheta \omega \mu \alpha \sigma \tau \dot{\alpha}, \quad \tau \dot{\alpha} \quad \mu \dot{\varepsilon} \nu$

CONJ CONJ marvelous.NOM.PL DEF.ART.NOM.PL PTCL

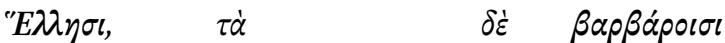

Greek.DAT.PL DEF.ART.NOM.PL PTCL barbarian.DAT.PL

$\dot{\alpha} \pi 0 \delta \varepsilon \chi \vartheta \dot{\varepsilon} v \tau \alpha, \quad \dot{\alpha} \times \lambda \varepsilon \hat{\alpha}$

display.PTCP.AOR.PASS.NOM.PL without.glory.NOM.PL 


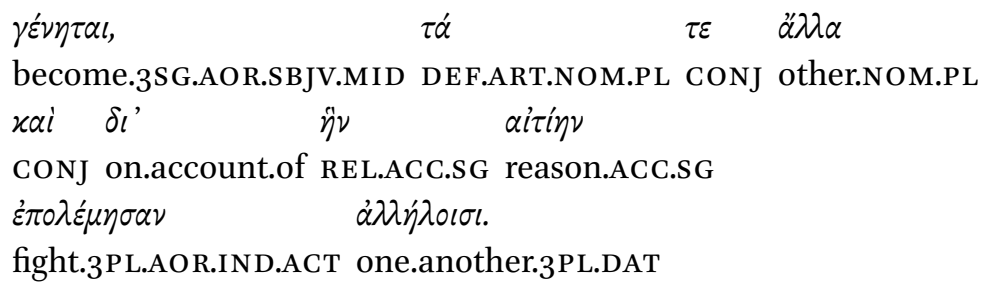
and in order that great and wonderous events, some performed by Greeks, some by barbarians, not lose their glory; and in particular what caused them to go to war against one another.' (Hdt. prooem.)

b. $\hat{\eta} \sigma \alpha \nu \quad \tau \hat{\omega} \iota \quad \Phi \alpha \dot{\nu} \eta \iota \quad \pi \alpha \hat{\delta} \varepsilon \varsigma$

be.3PL.IMPF.IND.ACT DEF.ART.DAT.Sg Phanes.DAT.SG child.NOM.PL

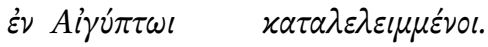

in Egypt.DAT.sg leave.behind.PTCP.PRF.MED.NOM.PL

'Children had been left behind by Phanes in Egypt.' (Hdt. 3.11.2)

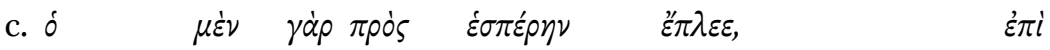
3SG.NOM PTCL for toward west.ACC.SG sail.3SG.IMPF.IND.ACT to

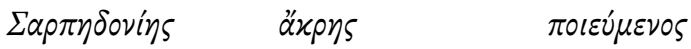
Sarpedon.GEN.SG headland.GEN.SG do.PTCP.PRES.MED.NOM.SG $\tau \dot{\eta} \nu \quad \ddot{\alpha} \pi l \xi \iota, \quad \dot{\varepsilon} \varsigma \quad \tau \dot{\eta} \nu \quad \alpha \dot{\tau} \omega \hat{\omega} \iota$ DEF.ART.ACC.SG arrival.ACC.SG into REL.ACC.SG 3 SG.DAT

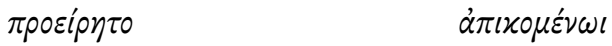
command.3SG.PLPF.MED.IND arrive.PTCP.PRES.MED.DAT.SG $\pi \varepsilon \rho \mu \mu \dot{v} \varepsilon \iota \nu$.

wait.INF.PRES.ACT

'For it (= the navy) was sailing westward, keeping its course for the headland of Sarpedon, where it had been ordered by him (= Xerxes) to wait for his arrival.' (Hdt. 7.58.2)

d. $\tau \circ \hat{\sigma} \sigma i \quad \tau \varepsilon \quad i \pi 0 \lambda \varepsilon l \pi \circ \mu \varepsilon \dot{v} \circ \sigma \sigma$

DEF.ART.DAT.PL CONJ leave.behind.PTCP.PRES.MED.DAT.PL

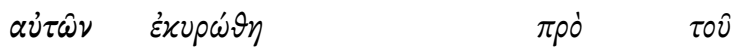
3PL.GEN decide.3SG.AOR.PASS.IND on.behalf DEF.ART.GEN.SG

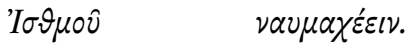

Isthmus.GEN.SG fight.INF.PRES.ACT

'And (it) was decided by the ones having been left behind to fight on behalf of the Isthmus.' (Hdt. 8.56.1) 
e. $\tau o ́ \tau \varepsilon \quad \delta \dot{\varepsilon} \quad \dot{\varepsilon} \pi i \tau \hat{\omega} \iota \quad A \sigma \omega \pi \hat{\omega} l \quad M a p \delta o v i \omega l$

then PTCL by DEF.ART.DAT.SG Asopus.DAT.Sg Mardonius.DAT.SG

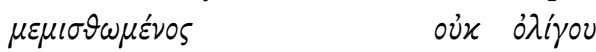

hire.PTCP.PRF.MED.NOM.SG NEG small.GEN.SG

'At that point (Hegesistratus) was by the Asopus, having been hired by Mardonius at no small price ...' (Hdt. 9.38.1)

(37) Dative agent predicted

a. $\varepsilon^{\prime} \tau l \quad \delta \dot{\varepsilon} \quad$ «

still PTCL ADD now by Persians.GEN.PL DEF.ART.NOM.SG

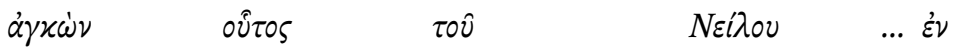

bend.NOM.SG DEM.NOM.SG DEF.ART.Gen.sg Nile.GEN.SG in

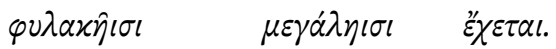

guarding.DAT.PL great.DAT.PL hold.3SG.PRES.MED.IND

'Even still to this day this bend of the Nile ... is carefully guarded by the

Persians.' (Hdt. 2.99.3)

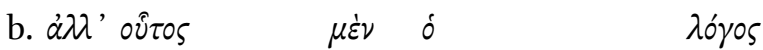

but DEM.NOM.SG PTCL DEF.ART.NOM.SG account.NOM.SG

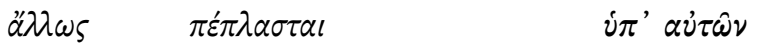

merely.ADV fabricate.3SG.PRF.MED.IND by self.GEN.PL

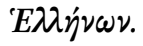

Greek.GEN.PL

'But this account has merely been fabricated by the Greeks themselves.' (Hdt. 4.77.2)

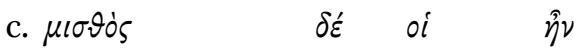

payment.NOM.SG PTCL 3SG.DAT be.3SG.IMPF.IND.ACT

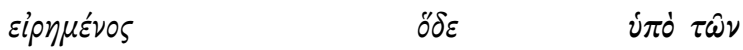

Say.PTCP.PRF.MED.NOM.SG DEM.NOM.SG by DEF.ART.GEN.PL

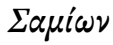

Samian.GEN.PL

'The following payment had been promised to him by the Samians ...' (Hdt. 6.23.5)

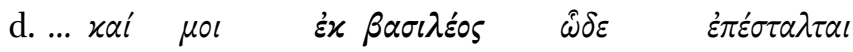
CONJ 1SG.DAT by king.GEN.SG thus.ADV order.3SG.PRF.MED.IND

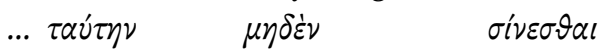

DEM.ACC.SG nothing.ACC.SG harm.INF.PRES.MED

'... And it has thus been ordered to me by the king to do this (land) no harm ...' (Hdt. 6.97.2) 


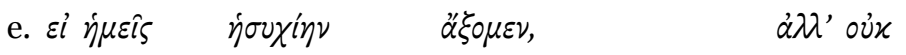

if 1PL.NOM peace.ACC.SG hold.1PL.FUT.ACT.IND but not

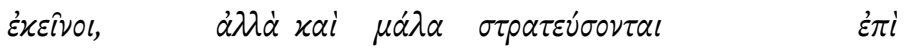

DEM.NOM.PL but ADD surely march.3PL.FUT.MED.IND against. $\tau \dot{\eta} \nu \quad \dot{\eta} \mu \varepsilon \tau \dot{\varepsilon} \rho \eta \nu, \quad \varepsilon \dot{l} \chi \rho \dot{\eta}$

DEF.ART.ACC.SG 1PL.POSS.ACC if be.necessary.3SG.PRES.ACT.IND

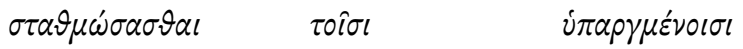
judge.INF.AOR.MED DEF.ART.DAT.PL initiate.PTCP.PRF.MED.DAT.PL

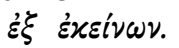

by DEM.GEN.PL

'If we are peaceful, they will not be, but will surely march against our land, if we are to judge by what has been initiated by them.' (Hdt. 7.11.2)

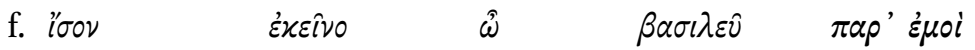
equal.NOM.SG DEM.NOM.SG vOC.PTCL king.VOC.SG by 1SG.DAT

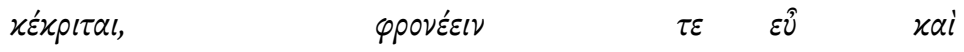
judge.3SG.PRF.MED.IND think.INF.PRES.ACT CONJ well.ADV CONJ

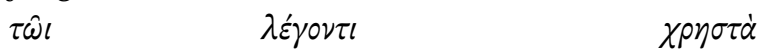

DEF.ART.DAT.SG say.PTCP.PRES.ACT.DAT.SG good.ACC.PL $\dot{\varepsilon} \vartheta \dot{\varepsilon} \lambda \varepsilon l \nu \quad \pi \varepsilon \hat{\imath} \vartheta \varepsilon \sigma \vartheta \alpha l$.

be.willing.INF.PRES.ACT obey.INF.PRES.MED

' $O$ king, that has been judged by me as equal, being wise and being willing to heed good advice.' (Hdt. 7.16. $\alpha .1$ )

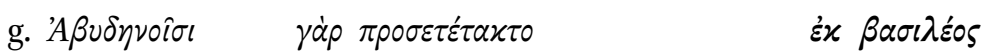

Abydian.DAT.PL for command.3SG.PLPF.MED.IND by king.GEN.SG

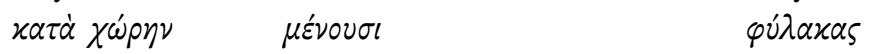

in land.ACC.SG remain.PTCP.PRES.ACT.DAT.PL guard.ACC.PL घival $\tau \hat{\omega} \nu \quad \gamma \varepsilon \varphi \cup \rho \varepsilon \dot{\omega} \nu$.

be.INF.PRES.ACT DEF.ART.GEN.PL bridge.GEN.PL

'For the Abydians had been ordered by the king to remain in their place and be guards of the bridges.' (Hdt. 7.95.2)

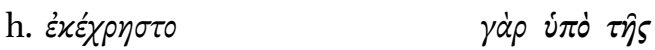

prophesy.3SG.PLPF.MED.IND for by DEF.ART.GEN.SG

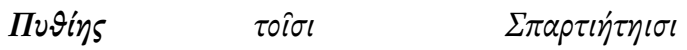

Pythian.GEN.SG DEF.ART.DAT.PL Spartan.DAT.PL

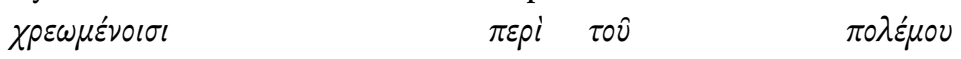

inquire.PTCP.PRES.MED.DAT.PL about DEF.ART.GEN.SG war.GEN.SG 


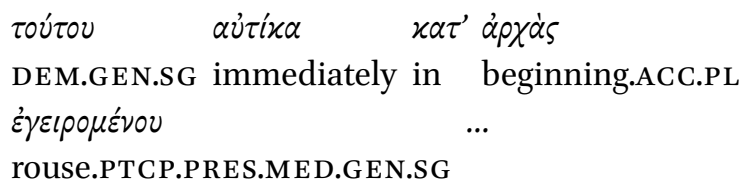

'For it was prophesied by the Pythia to the Spartans who consulted the oracle about this war when it initially broke out ...' (Hdt. 7.220.3)

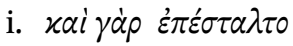

$$
\dot{\varepsilon}^{\prime} \xi \pi \iota \dot{\lambda} \lambda \tau \varepsilon \omega
$$

in.fact order.3SG.PLPF.MED.IND by Epialtes.GEN.SG thus.ADV

'In fact it had been ordered thus by Epialtes.' (Hdt. 7.223.1)

Although the errors run in both directions, dative agents were incorrectly predicted more often than prepositional phrase agents. It is unclear what accounts for Herodotus' selection of agent phrase in these examples. One possibility is that there are lexical effects that have yet to be fully explored.

\subsection{Bayes factor}

The Bayes factor is the ratio of the marginal likelihoods of two competing models:

$$
B F_{10}=\frac{p\left(y \mid M_{1}\right)}{p\left(y \mid M_{0}\right)}
$$

$P(y \mid M)$ is the probability of the data $y$ given model $M$ and $B F_{10}$ denotes the extent to which the data support model $M_{1}$ over model $M_{0}$. Bayes factors thus measure how likely the observed data are under one model compared to an alternative model. It is worth highlighting that Bayes factors measure the relative fit of a model to data. They do not measure model adequacy (see further Jäger 2019). One of the advantages of Bayes factors is that they penalize models with too much structure, which wards off overfitting. I interpret log Bayes factors according to the discrete categories in Table 8 (cf. Jeffreys 1961: 432; Kass \& Raferty 1995: 791).

Table 9 presents the Bayes factors for the three models under consideration. The first row compares the model of George 2005 to the traditional model. Support for George's model is decisive. The second row compares the proposed model to that of George 2005. The evidence decisively favors the proposed model. One reason that the proposed model improves on that of George 2005 is that the $95 \%$ credible interval for the participial factor in Table 4 above (Section 5.1) includes zero. It is quite possible that this factor has no effect on agent realization and it is precisely parameters of this sort that Bayes factors penalize. 
TABLE 8 The interpretation of log Bayes factors (Höhna et al. 2017: 27)

\begin{tabular}{ll} 
Strength of evidence & $\log \left(\mathrm{BF}_{\mathbf{1 0}}\right)$ \\
\hline Negative (supports $\left.\mathrm{M}_{1}\right)$ & $<\mathrm{o}$ \\
Barely worth mentioning & o to 1.16 \\
Substantial & 1.16 to 2.3 \\
Strong & 2.3 to 4.6 \\
Decisive & $>4.6$
\end{tabular}

TABLE 9 Comparison of $\log$ Bayes factors

\begin{tabular}{lll}
\hline Model 1 & Model o & $\log \left(\mathrm{BF}_{\mathbf{1 0}}\right)$ \\
\hline George 2005 & Traditional model & 44 \\
Proposed model & George 2005 & 28.4 \\
\hline
\end{tabular}

\subsection{Bayesian $\mathrm{R}^{2}$}

Finally, the Bayesian $R^{2}$ measures how much of the variability in the data is accounted for by the model (Gelman et al. 2019). Table 10 reports both the conditional and marginal $R^{2}$ values for each model. The marginal $R^{2}$ values only take into account the fixed effects (i.e., the predictor variables), whereas the conditional $R^{2}$ takes into account both the fixed effects and the varying intercepts. The difference between these two values for each of the models reflects the correlation between passive agent realization and predicate. The proposed model accounts for more of the variability in the data than the other two models.

\section{$8 \quad$ Conclusion}

The overarching claim of my analysis is that differential agent marking in Herodotus is conditioned by the relationship between semantic role and referential prominence. When semantic role and referential prominence are aligned, dative agents are favored. When they are not, prepositional phrase agents predominate. Although grammatical aspect has long been thought to be the paramount conditioning factor of passive agent variation, my investi- 
TABLE 10 Conditional and marginal Bayesian $R^{2}$ values

\begin{tabular}{llllll} 
Model & Component & $\boldsymbol{R}^{2}$ & SD & CI-low & CI-high \\
\hline \multirow{2}{*}{ Traditional } & Conditional & 0.78 & 0.02 & 0.73 & 0.83 \\
& Marginal & 0.51 & 0.06 & 0.35 & 0.61 \\
\multirow{2}{*}{ George 2005 } & Conditional & 0.84 & 0.02 & 0.79 & 0.88 \\
& Marginal & 0.69 & 0.01 & 0.66 & 0.71 \\
Proposed & Conditional & 0.89 & 0.02 & 0.85 & 0.92 \\
& Marginal & 0.74 & 0.01 & 0.69 & 0.75 \\
\hline
\end{tabular}

gation has revealed that this is not in fact the case. The prosodic phonology and nominality of the agent is a much stronger determinant of passive agents. This synchronic study of passive agent variation provides the foundation for an adequate diachronic investigation of agent marking. Goldstein (2019) provides a first sketch of the diachronic trajectory from Homer to Herodotus, but there remains much more to say about this topic.

I end with a comment on the importance of the methods used in this study. Morphosyntactic variation is complex and typically conditioned by a variety of factors (cf. Danckaert 2017: 80), but the methods of traditional philological analysis alone by and large limit scholars to monofactorial accounts (as witnessed by the early research on differential agent marking in Greek). The methods of regression analysis used in this study enable us to progress beyond monofactorial analyses to meet the demands of the data. Regression modeling in particular and quantitative methods in general are thus essential if we hope to understand why languages vary as they do (cf. Fischer 2007: 44; Hilpert \& Gries 2017; Jenset \& McGillivray 2017; Danckaert 2017: 79).

The dataset and code for this study are archived at https://doi.org/10.5281/ zenodo.4453719.

\section{Acknowledgments}

For instructive criticism on earlier versions of this paper, I would like to thank Andrew Garrett, Donald Mastronarde, Freek van de Velde, Tony Yates, and audiences at the Ninth International Colloquium on Ancient Greek Linguistics in Helsinki (in particular James Tauber and Robert Crellin) and the 2019 meeting of the Society for Classical Studies. I am grateful to the statistical consultants at the Institute for Digital Research and Education (IDRE) for looking over 
the statistical sections of the manuscript. The comments of two anonymous reviewers improved several aspects of the paper. Fault for all remaining errors lies solely with me.

\section{References}

Agresti, Alan. 2013. Categorical data analysis. 3rd edn. Hoboken: Wiley.

Aissen, Judith. 2003. Different object marking. Iconicity vs. economy. Natural Language \& Linguistic Theory 21.435-483.

Ariel, Mira. 199o. Accessing NP antecedents. London: Routledge.

Barth, Danielle \& Vsevolod Kapatsinski. 2018. Evaluating logistic mixed-effects models of corpus-linguistic data. Mixed-effects regression models in linguistics, ed. by Dirk Speelman, Kris Heylen, \& Dirk Geeraerts, 99-116. Berlin: Springer.

Bavant, Marc. 2008. Proto-Indo-European ergativity ... still to be discussed. Poznań Studies in Contemporary Linguistics 44.433-447.

Bentein, Klaas. 2014. Perfect. Encyclopedia of ancient Greek language and linguistics, ed. by Georgios K. Giannakis, 46-49. Vol. 3: P-Z. Leiden: Brill.

Bossong, Georg. 1985. Empirische Universalienforschung: Differentielle Objektmarkierung in den neuiranischen Sprachen. Tübingen: Narr.

Bossong, Georg. 1991. Differential object marking in Romance and beyond. New analyses in Romance linguistics, ed. by Dieter Wanner \& Douglas A. Kibbee, 143-170. Amsterdam: John Benjamins.

Bresnan, Joan W., Anna Cueni, Tatiana Nikitina, \& R. Harald Baayen. 2007. Predicting the dative alternation. Cognitive foundations of interpretation, ed. by Gerlof Bouma, Irene Kramer, \& Joost Zwarts, 69-94. Amsterdam: Royal Netherlands Academy of Science.

Brookes, James W.R. 2014. Probabilistic and multivariate modelling in Latin grammar. The participle-auxiliary alternation as a case study. $\mathrm{PhD}$ thesis. University of Manchester.

Bürkner, Paul-Christian. 2017. brms. An R package for Bayesian multilevel models using Stan. Journal of Statistical Software 80.1-28.

Calabrese, Andrea. 2008. On absolute and contextual syncretism. Remarks on the structure of case paradigms and on how to derive them. Inflectional identity, ed. by Andrew Nevins \& Asef Bachrach, 156-205. Oxford: Oxford University Press.

Chantraine, Pierre. 1927. Histoire du parfait grec. Paris: Klincksieck.

Comrie, Bernard. 1976. Aspect. Cambridge: Cambridge University Press.

Comrie, Bernard. 1978. Ergativity. Syntactic typology: Studies in the phenomenology of language, ed. by Winfred P. Lehmann, 329-394. Austin: University of Texas.

Comrie, Bernard. 1989. Language universals and linguistic typology: Syntax and morphology. 2nd edn. Chicago: University of Chicago Press. 
Danckaert, Lieven. 2017. The development of Latin clause structure: A study of the extended verb phrase. Oxford: Oxford University Press.

Danesi, Serena, Cynthia A. Johnson, \& Jóhanna Barðdal. 2017. Between the historical languages and the reconstructed language. An alternative approach to the gerundive + "dative of agent" construction in Indo-European. Indogermanische Forschungen 122.143-188.

Dixon, Robert M.W. 1979. Ergativity. Language 55·59-138.

Dowty, David R. 1991. Thematic proto-roles and argument selection. Language 67.547619 .

Fischer, Olga. 2007. Morphosyntactic change: Functional and formal perspectives. Oxford: Oxford University Press.

Forker, Diana 2013. Differential agent marking in Hinuq. Argument structure in flux: The Naples-Capri papers, ed. by Elly van Gelderen, Michela Cennamo, \& Jóhanna Barðdal, 33-52. Amsterdam: John Benjamins.

Ganenkov, Dmitry, Timur Maisak, \& Solmaz Merdanova. 20o8. Non-canonical agent marking in Agul. Differential subject marking, ed. by Helen de Hoop \& Peter de Swart, 173-198. Dordrecht: Springer.

Gelman, Andrew, Ben Goodrich, Jonah Gabry, \& Aki Vehtari. 2019. R-squared for Bayesian regression models. The American Statistician 73.307-309.

George, Coulter H. 2005. Expressions of agency in ancient Greek. Cambridge: Cambridge University Press.

Goldstein, David M. 2016. Classical Greek syntax: Wackernagel's Law in Herodotus. Leiden: Brill.

Goldstein, David M. 2019. The synchrony and diachrony of the Greek dative of agent. QAZZU warrai: Anatolian and Indo-European studies in honor of Kazuhiko Yoshida, ed. by Adam Catt, Ronald I. Kim, Masato Kobayashi, \& Brent H. Vine, 73-9o. Ann Arbor: Beech Stave Press.

Green, Alexander. 1913. The dative of agency. New York: Columbia University Press.

Gries, Stefan Th. 2003. Multifactorial analysis in corpus linguistics: A study of particle placement. London: Bloomsbury.

Gries, Stefan Th. 2015. The most under-used statistical method in corpus linguistics. Multi-level and mixed-effects models. Corpora $10.95^{-125}$.

Haspelmath, Martin. 1992. From resultative to perfect in ancient Greek. Nuevos estudios sobre construcciones resultativos, ed. by José Luis Leza Iturrioz, 187-224. Universidad de Guadalajara: Centro de Investigación de Lenguas Indígenas.

Haspelmath, Martin. 2021. Role-reference associations and the explanation of argument coding splits. Linguistics 59.1-52.

Haug, Dag T.T. 2008. From resultatives to anteriors in ancient Greek. On the role of paradigmaticity in semantic change. Grammatical change and linguistic theory: The Rosendal papers, ed. by Thórhallur Eythórsson, 285-305. Amsterdam: John Benjamins. 
Hettrich, Heinrich. 1990. Der Agens in passivischen Sätzen altindogermanischer Sprachen. Göttingen: Vandenhoeck \& Ruprecht.

Hilpert, Martin \& Stefan Th. Gries. 2017. Quantitative approaches to diachronic corpus linguistics. The Cambridge handbook of English historical linguistics, ed. by Merja Kytö \& Paivi Pahta, 36-53. Cambridge: Cambridge University Press.

Höhna, Sebastian, Michael J. Landis, \& Tracy A. Heath. 2017. Phylogenetic inference using RevBayes. Current Protocols in Bioinformatics 57.6.16.1-6.16.34.

Ishizuka, Tomoko. 2012. The passive in Japanese: A Cartographic Minimalist approach. Amsterdam: John Benjamins.

Jäger, Gerhard. 2019. Model evaluation in computational historical linguistics. Theoretical Linguistics 45.299-307.

Jamison, Stephanie W. 1979a. Remarks on the expression of agency with the passive in Vedic and Indo-European. Zeitschrift für vergleichende Sprachforschung 93.196-219. Jamison, Stephanie W. 1979b. The case of the agent in Indo-European. Die Sprache 25.129-143.

Jannaris, Antonius N. 1897. An historical Greek grammar: Chiefly of the Attic dialect as written and spoken from classical antiquity down to the present time, founded upon the ancient texts, inscriptions, papyri and present popular Greek. London: Macmillan.

Jeffreys, Harold. 1961. Theory of probability. 3rd edn. Oxford: Oxford University Press.

Jenset, Gard B. \& Barbara McGillivray 2017. Quantitative historical linguistics. Oxford: Oxford University Press.

Kass, Robert E. \& Adrian E. Raferty. 1995. Bayes factors. Journal of the American Statistical Association 90.773-795.

Kiparsky, Paul. 1998. Partitive case and aspect. Lexical and compositional factors. The projection of arguments, ed. by Miriam Butt \& Wilhelm Geuder, 265-307. Stanford: Center for the Study of Language and Information.

Kiparsky, Paul. 2008. Universals constrain change; change results in typological generalizations. Linguistic universals and language change, ed. by Jeff Good, 23-53. Oxford: Oxford University Press.

Kittilä, Seppo. 2005. Remarks on involuntary agent constructions. WORD 56.381-419.

Krüger, Karl Wilhelm. 2003. Greek syntax: Early Greek poetic and Herodotean syntax. Trans. by Guy L. Cooper III. Vol. 3. Ann Arbor: University of Michigan Press.

Kühner, Raphael \& Bernhard Gerth. 1898. Ausführliche Grammatik der griechischen Sprache: Satzlehre. 3rd ed. Vol. 1. Hanover: Hahn.

Lüdecke, Daniel, Mattan S. Ben-Shachar, Indrajeet Patil, Philip Waggoner, \& Dominique Makowski. 2021. Assessment, testing and comparison of statistical models using R. Journal of Open Source Software 6.3132. DOI: 10.21105/joss.03132.

Luraghi, Silvia. 1987. Patterns of case syncretism in Indo-European languages. Papers from the 7 th International Conference on Historical Linguistics, ed. by Anna Giacalone Ramat, Onofrio Carruba, \& Giuliano Bernini, 355-371. Amsterdam:John Benjamins. 
Malchukov, Andrej L. 2015. Towards a typology of split ergativity. A TAM-hierarchy for alignment splits. Scales and hierarchies: A cross-disciplinary perspective, ed. by Ina Bornkessel-Schlesewsky, Andrej L. Malchukov, \& Marc D. Richards, 275-296. Berlin: de Gruyter.

Malchukov, Andrej L. \& Helen de Hoop 2011. Tense, aspect, and mood based differential case marking. Lingua 121.35-47.

McGregor, William B. 20og. Typology of ergativity. Language and Linguistics Compass $3.480-508$.

McGregor, William B. 2010. Optional ergative case marking systems in a typologicalsemiotic perspective. Lingua 120.1610-1636.

McGregor, William B. \& Jean-Christophe Verstraete. 2010. Optional ergative marking and its implications for linguistic theory. Lingua 120.1607-16o9.

Moravcsik, Edith A. 1978. On the limits of subject-object ambiguity. Papers in Linguistics $11.255^{-269}$.

Nicenboim, Bruno \& Shravan Vasishth. 2016. Statistical methods for linguistic research. Foundational ideas - Part II. Language and Linguistics Compass 10.591-613.

Petersen, Walter. 1918a. Syncretism in the Indo-European dative. The American Journal of Philology 39.1-26.

Petersen, Walter. 1918b. Syncretism in the Indo-European dative. The American Journal of Philology 39.117-144.

Piñón, Christopher. 20o9. Agent-oriented adverbs as manner adverbs. Ereignissemantik-Workshop, Humboldt-Universität, Berlin.

Piñón, Christopher. 2010. What to do with agent-oriented adverbs. Handout, Speaking

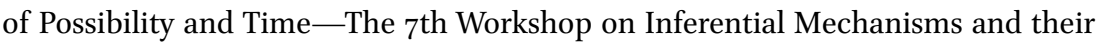
Linguistic Manifestation, Göttingen.

Powell, John Enoch. 1938. A lexicon to Herodotus. Cambridge: Cambridge University Press.

R Core Team 2019. R. A language and environment for statistical computing. Vienna: $\mathrm{R}$ Foundation for Statistical Computing. https://www.r-project.org.

Schwyzer, Eduard. 1988. Griechische Grammatik: Syntax und syntaktische Stilistik. $5^{\text {th }}$ edn. Vol. 2. München: C.H. Beck.

Silverstein, Michael. 1976. Hierarchy of features and ergativity. Grammatical categories in Australian languages, ed. by Robert M.W. Dixon, 112-171. Canberra: Australian Institute of Aboriginal Studies.

Smyth, Herbert Weir. 1956. Greek grammar. 2nd edn. Cambridge, MA: Harvard University Press.

Wackernagel, Jacob. 1904. Studien zum griechischen Perfektum. Göttingen: Vandenhoeck \& Ruprecht.

Wackernagel, Jacob. 20o9. Jacob Wackernagel, Lectures on syntax: With special reference to Greek, Latin, and Germanic. Trans. by David Langslow. Oxford: Oxford University Press. 
Willi, Andreas. 2018. Origins of the Greekverb. Cambridge: Cambridge University Press. Wolk, Christoph, Joan Bresnan, Anette Rosenbach, \& Benedikt Szmrecsanyi. 2013. Dative and genitive variability in late modern English. Exploring cross-constructional variation and change. Diachronica $30.382-419$.

Yamashita Smith, Tomoko. 2005. Affectedness constructions. How languages indicate positive and negative events. PhD Thesis. University of California, Berkeley.

Yamashita Smith, Tomoko. 2010. Cross-linguistic categorization of benefactives by event structure. A preliminary framework for benefactive typology. In Zúñiga \& Kittilä, $71-96$.

Zúñiga, Fernando \& Seppo Kittilä, eds. 2010. Benefactives and malefactives: Typological perspectives and case studies. Amsterdam: John Benjamins. 


\section{Appendix}

TABLE 11 Personal pronouns in Herodotus

\begin{tabular}{|c|c|c|c|c|}
\hline Person & Case & Number & Form & Prosody \\
\hline 1 & GEN & SG & $\mu \varepsilon o$ & Enclitic \\
\hline 1 & GEN & SG & $\mu \varepsilon v$ & Enclitic \\
\hline 1 & GEN & SG & $\mu o v$ & Enclitic \\
\hline 1 & GEN & SG & દ̇ $\mu \varepsilon^{\prime}$ & Stressed \\
\hline 1 & GEN & SG & 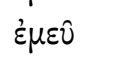 & Stressed \\
\hline 1 & DAT & SG & $\mu \mathrm{ol}$ & Enclitic \\
\hline 1 & DAT & SG & 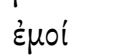 & Stressed \\
\hline 1 & ACC & SG & $\mu \varepsilon$ & Enclitic \\
\hline 1 & ACC & SG & $\varepsilon \mu \varepsilon^{\prime}$ & Stressed \\
\hline 2 & GEN & SG & $\sigma \varepsilon \circ$ & Enclitic \\
\hline 2 & GEN & SG & $\sigma \varepsilon v$ & Enclitic \\
\hline 2 & GEN & SG & бov? & Enclitic \\
\hline 2 & GEN & SG & $\tau \varepsilon \cup ?$ & Enclitic \\
\hline 2 & GEN & SG & бદ́o & Stressed \\
\hline 2 & GEN & SG & 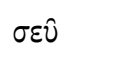 & Stressed \\
\hline 2 & DAT & SG & $\sigma \circ \mathrm{l}$ & Enclitic \\
\hline 2 & DAT & SG & $\tau O l$ & Enclitic \\
\hline 2 & DAT & SG & бoí & Stressed \\
\hline 2 & DAT & SG & $\tau o i ́$ & Stressed \\
\hline 2 & DAT & SG & $\tau \varepsilon \ddot{\imath} \nu ?$ & Stressed \\
\hline 2 & ACC & SG & $\sigma \varepsilon$ & Enclitic \\
\hline 2 & ACC & SG & $\sigma \dot{\varepsilon}$ & Stressed \\
\hline 3 & GEN & SG & घर्v & Enclitic \\
\hline 3 & GEN & SG & $\alpha \cup ่ \tau o v ̂$ & Stressed \\
\hline 3 & DAT & SG & oi & Enclitic \\
\hline 3 & DAT & SG & $\alpha \dot{\tau} \tau \hat{\omega} \iota$ & Stressed \\
\hline 3 & ACC & SG & है & Enclitic \\
\hline 3 & ACC & SG & $\mu l \nu$ & Enclitic \\
\hline 3 & ACC & SG & viv & Enclitic \\
\hline 3 & ACC & SG & 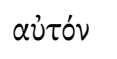 & Stressed \\
\hline 1 & GEN & PL & $\dot{\eta} \mu \dot{\varepsilon} \omega \nu$ & Stressed \\
\hline
\end{tabular}


TABEL 11 Personal pronouns in Herodotus (cont.)

\begin{tabular}{|c|c|c|c|c|}
\hline Person & Case & Number & Form & Prosody \\
\hline 1 & DAT & PL & $\dot{\eta} \mu \hat{\imath} \nu$ & Stressed \\
\hline 1 & ACC & PL & $\dot{\eta} \mu \varepsilon \dot{\varepsilon} \alpha \varsigma$ & Stressed \\
\hline 2 & GEN & PL & $i \mu \varepsilon \dot{\varepsilon} \omega \nu$ & Stressed \\
\hline 2 & DAT & $\mathrm{PL}$ & $\dot{v} \mu \hat{\imath} \nu$ & Stressed \\
\hline 2 & ACC & PL & $i \mu \varepsilon \alpha \varsigma$ & Stressed \\
\hline 3 & GEN & PL & $\sigma \varphi \varepsilon \dot{\varepsilon} \omega \nu$ & Stressed \\
\hline 3 & GEN & PL & $\sigma \varphi \varepsilon \omega \nu$ & Enclitic \\
\hline 3 & GEN & PL & $\alpha \dot{\tau} \tau \hat{\omega} \nu$ & Stressed \\
\hline 3 & DAT & $\mathrm{PL}$ & $\sigma \varphi l(\nu)$ & Enclitic \\
\hline 3 & DAT & $\mathrm{PL}$ & $\sigma \varphi ı l(\nu)$ & Enclitic \\
\hline 3 & DAT & PL & $\alpha$ & Stressed \\
\hline 3 & ACC & PL & $\sigma \varphi \varepsilon \alpha \varsigma$ & Enclitic \\
\hline 3 & ACC & PL & 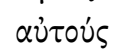 & Stressed \\
\hline 3 & ACC & PL & $\sigma \varphi \varepsilon(\alpha)$ & Enclitic \\
\hline
\end{tabular}

